\title{
Parents' Economic Support of Young-Adult Children: Do Socioeconomic Circumstances Matter?
}

\author{
Deborah Cobb-Clark* Tue Gørgens ${ }^{\dagger}$
}

2013-07-10

\begin{abstract}
We assess how the support parents provide to young adults as they leave school and begin working is related to their family's socioeconomic circumstances. We do this using an innovative Australian data set which merges survey and administrative data. The survey data inform us about intergenerational co-residence and financial gifts and the administrative data about the family's welfare-receipt history. We find that disadvantaged young people are more likely to be economically independent of their parents than are their more advantaged peers. This disparity is larger for financial gifts than for coresidence and increases with age. Moreover, there is a complex relationship between parental support and participation in study and work. We find no evidence, however, that a lack of parental support is the source of the socioeconomic gradient in either studying or employment. These results are important in eliminating one potential pathway through which socioeconomic disadvantage limits young people's outcomes.
\end{abstract}

Keywords: co-residence, financial gifts, socioeconomic disadvantage, youth outcomes

JEL codes: J12, J13, J22, J24

Acknowledgement: This research was supported in part by a grant from the Australian Research Council (DP0989021).

*Address: Melbourne Institute of Applied Economic and Social Research, Level 7, Alan Gilbert Building, 161 Barry Street, The University of Melbourne, Victoria 3010, Australia. E-mail: deborah.cobbclark@anu.edu.au.

$\dagger$ Address: Research School of Economics, H W Arndt Building 25A, The Australian National University, Canberra ACT 0200, Australia. E-mail: tue.gorgens@anu.edu.au. 


\section{Introduction}

Parental support in the form of co-residence or financial gifts can play an important role in ensuring that young people make a successful transition into adult roles. The option of living with one's parents allows young people to consume, save and invest even in the face of credit constraints (e.g. Cox, 1990; Folgi, 2000; Ermisch, 2003) and to insure themselves against bad labor market outcomes (e.g. McElroy, 1985; Card and Lemieux, 2000; Kaplan, 2010) or relationship breakdowns (e.g. Hamon, 1995). Similarly, parents' financial assistance in meeting the costs of education and training is linked to their adult children enjoying higher living standards primarily as a result of improved labor market opportunities (e.g. Semyonov and Lewin-Epstein, 2001).

Unfortunately, not all young people have access to the parental support they want and/or need. Some families lack the necessary resources, while others may simply be unwilling to continue supporting children after they reach adulthood (e.g. Aquilino, 2005). As a result, families can vary substantially in the level and type of support they provide to their adult children and the circumstances in which they provide it (e.g. Semyonov and Lewin-Epstein, 2001). The lack of consensus may result in young people having unrealistic expectations about the support they can count on (e.g. Goldscheider et al., 2001).

This paper investigates the links between young adults' family circumstances and the economic support they receive from their parents as they make investments in education and work. We are particularly interested in the following questions. First, is the support parents provide to their young-adult children related to their social and economic disadvantage? Second, is a young person's propensity to be studying or working related to the parental support he or she is receiving? Third, is the link between socioeconomic disadvantage and young people's outcomes attributable to disparities in the parental support they receive? In addressing these questions, we focus explicitly on the economic support provided through direct financial gifts as well as through intergenerational co-residence.

Specifically, we take advantage of unique data from the Australian Youth in Focus (YIF) Project. The YIF Project interviewed young adults at age 18 and again at age 20 about their living arrangements, the financial support they receive from their parents, 
their current educational and employment activities, and their family background (e.g. parents' educational attainment, occupation, and employment history). These survey data are then matched to administrative data on the family's welfare receipt while the young person was growing up. The linking of survey and administrative data is one of the key innovations of the paper. The survey data allow us to assess the link between young people's outcomes, parents' economic support, and family background, while the administrative data are used to construct a novel measure of socioeconomic disadvantage based on welfare receipt rather than parental income, education or occupation.

Our analysis is inherently descriptive. Identifying causal relationships is not possible without resorting to overly stylized structural models and maintained assumptions about the nature of intra-household decision making. In contrast, our analysis sheds light on the pathways through which disadvantage influences young-adult outcomes and on the options for reducing the impact of that disadvantage.

We make several important contributions. First, we take a broad perspective by considering the parental support provided to young people through both co-residence and financial gifts. This is an improvement over some previous studies which are more narrowly focused on one form of support or the other. ${ }^{1}$ Second, socioeconomic status is commonly assessed using some combination of parental income, education and/or occupational status (e.g. D'Addio, 2007, p27). However, we are able to account for actual episodes of disadvantage (i.e. welfare receipt) in addition to these important background factors. A family's welfare experience is about more than the narrow receipt of public assistance per se, but also reflects the broader family circumstances, i.e. unemployment, poverty, family breakdown, single parenthood, etc., which led the family to require social assistance in the first place. Thus, our measure captures the experience of socioeconomic disadvantage in a much broader sense than traditional measures which are more narrowly linked to to family resources. Finally, we are aware of no other study which directly assesses whether the negative effect of socioeconomic disadvantage on young-adult outcomes

\footnotetext{
${ }^{1}$ See for example, Bernheim et al. (1985), Cox (1987), Cox and Jakubson (1995), and Guiso and Jappelli (2002) on financial transfers and Wolf and Soldo (1989) and Ermisch and Di Salvo (1997) on co-residence.
} 
that is frequently observed can be traced to a lack of support from their parents.

We find that young people who experience socioeconomic disadvantage are more likely to be residentially and financially independent of their parents than are their peers growing up in more advantaged circumstances. This disparity is larger for financial gifts than for co-residence and increases as young people age. Moreover, there is a complex relationship between parental support and a young person's engagement in study and work. These links are generally stronger at age 20 than at age 18 and are often stronger for advantaged than for disadvantaged youths. We find no evidence, however, that a lack of parental support explains the socioeconomic gradient in either studying or employment. These results are important in eliminating one potential pathway through which socioeconomic disadvantage limits young people's outcomes.

This paper is organized as follows. Section 2 summarizes the theoretical and empirical background for the analysis. Section 3 discusses empirical strategies and explains our descriptive approach. The details of the YIF data, our estimation sample, and key variables are provided in Section 4. Section 5 discusses our main results, while detailed results can be found in the appendix. Our conclusions and suggested directions for future research are discussed in Section 6.

\section{Literature Review}

Over the past 20 years or so, parents' support of their adult children, either through joint living arrangements or through financial transfers, has begun to receive explicit attention in the international literature. ${ }^{2}$ Economists have been instrumental in developing theoretical models of the family's decision-making process surrounding alternative forms of support. In particular, researchers often adopt a noncooperative game theoretic framework when modelling the interaction between parents and their adolescent children (e.g. McElroy, 1985; Weinberg, 2001; Kooreman, 2004; Hao et al., 2008; Lundberg et al., 2007). Unlike the cooperative approach taken in understanding bargaining between spouses, ado-

\footnotetext{
${ }^{2}$ More recent research has also considered the effects of time transfers, particularly in the form of care for grandchildren, between mothers and their adult daughters (e.g. Dimova and Wolff, 2010).
} 
lescents are better seen as economic agents with independent preferences and the power to influence family outcomes (e.g. Lundberg et al., 2007).

In this context, co-residence can be seen as a form of inter-familial transfer similar to other inter vivos transfers. ${ }^{3}$ Thus, the decision to co-reside rests upon a comparison of the indirect utility when parents live with their adult children and when they do not. Parents are usually assumed to have altruistic preferences, and the public-good nature of housing implies that co-residence is a less expensive way of transferring resources to children than providing financial transfers directly. At the same time, co-residence may involve additional costs resulting from a lack of privacy and independence (e.g. McElroy, 1985; Ermisch and Di Salvo, 1997; Ermisch, 1999, 2003; Laferrère and Bessière, 2003; Le Blanc and Wolff, 2006; Laferrère, 2006).

Perhaps not surprisingly, the theoretical literature has produced a range of predictions about the key relationships underpinning parents' support for their young-adult children. In particular, models of intergenerational co-residence and financial transfers rely heavily on maintained assumptions regarding, for example, the form of parents' preferences (i.e. altruistic versus paternalistic); the nature of household bargaining (i.e. cooperative versus noncooperative); the costs and benefits of intergenerational co-residence; the exogeneity (or not) of parents' housing decisions; and the motivation for leaving home. Different assumptions can give rise to different and contradictory predictions, and similar predictions can arise from quite different assumptions. ${ }^{4}$

The empirical literature, on the other hand, has been largely concerned with assessing whether and how parental support for young adults is targeted. U.S. parents, for example, appear to use co-residence and financial transfers to subsidize their children's investments in education (e.g. Keane and Wolpin, 2001; Rosenzweig and Wolpin, 1993). Similarly Spanish parents use co-residence as a means of helping their children who are either studying or do not have a job (e.g. Martínez-Granado and Ruiz-Castillo, 2002). The targeted nature of parental support is consistent with parents having paternalistic rather

\footnotetext{
${ }^{3}$ See Cobb-Clark (2008) for a review of the literature surrounding the co-residence decision.

${ }^{4}$ See, for example, the predictions in Ermisch (2003), Manacorda and Moretti (2006), and Laferrère (2006) regarding the relationship between parental income and young people's propensity to live at home.
} 
than altruistic preferences (e.g. Pollak, 1988). In other words, parents may care about their children's characteristics (i.e. educational attainment) or behavior (i.e. employment status) rather than their utility or wellbeing per se.

\section{Empirical Model}

Empirical analysis of the causal effects of parental support is hampered by the fact that parents' economic support and young-adult children's educational and labor market investments are jointly determined. While structural estimation may be feasible, as mentioned above, results will be sensitive to the particular theoretical framework adopted. Similarly, instrumental variables estimation may also be feasible, but the validity of the instruments will depend on the specific theoretical model assumed.

The empirical literature has taken a variety of approaches to dealing with this challenge. Some researchers simply assume that parents' economic support is exogenous with respect to young people's activities and interpret estimated effects as causal (e.g. Pabilonia, 2001; Oettinger, 2005). Others model the relationship between parental support and the activities of adolescent (as opposed to young adult) children, because the fact that virtually all adolescents live at home and attend school makes the problem much simpler. In particular, researchers interested in the effect of parents' financial transfers on their adolescent children's labor supply have used simultaneous equation models (e.g. Wolff, 2006; Dustmann et al., 2009) or fixed-effects two-stage least squares estimation (e.g. Gong, 2009). Matters become much more complicated when the potential tradeoffs between alternative forms of parental support and young adults' (as opposed to adolescents') activities are considered. Researchers attempting to disentangle the effects of parental support on young adults' human capital investments usually focus on only a subset of these relationships and rely on theoretical restrictions or ad hoc empirical exclusion restrictions for identification (e.g. Kalenkoski, 2008; Rosenzweig and Wolpin, 1993; Keane and Wolpin, 2001; Kalenkoski and Pabilonia, 2010; Martínez-Granado and Ruiz-Castillo, 2002).

Given that we consider co-residence, financial gifts, educational investments and em- 
ployment jointly, we are reluctant to rely on untestable theoretical restrictions or dubious empirical exclusion restrictions to achieve causal identification. For this reason, we conduct a descriptive analysis. Specifically, we focus on describing how parental support in the form of co-residence and financial gifts vary with socioeconomic disadvantage and family background and how young people's educational and employment activities vary with parents' economic support, socioeconomic disadvantage and family background. We avoid interpreting our estimates as causal effects.

We estimate the relationship between parental support and youths' activities using the following model. Let $S$ denote the type of support parents provide to the youth, and let $A$ denote the youth's educational and employment activity. We assume that $S$ and $A$ are discrete random variables, with $S \in\left\{s_{1}, \ldots, s_{K_{s}}\right\}$ categories of support and $A \in\left\{a_{1}, \ldots, a_{K_{a}}\right\}$ categories of activities. As explained below we distinguish between families who experienced no, moderate, or extensive socioeconomic disadvantage while the youth was growing up. Let $G$ denote the family's socioeconomic circumstances, with $G \in\left\{g_{1}, g_{2}, g_{3}\right\}$. Finally, $X$ represents a vector of other family background characteristics, lowercase letters denote particular values of random variables, and Greek letters denote unknown parameter vectors.

We assume that parental support $S$ conforms to a multinomial logit model,

$$
\operatorname{Pr}(S=s \mid G=g, X=x)=\frac{\exp \left(\alpha_{s}+x^{\prime} \beta_{s}+\tilde{g}^{\prime} \mu_{s}\right)}{\sum_{j=1}^{K_{s}} \exp \left(\alpha_{j}+x^{\prime} \beta_{j}+\tilde{g}^{\prime} \mu_{j}\right)},
$$

where $\tilde{G}$ is a vector of zeros and a single one indicating the category of socioeconomic circumstances. That is, if $G=g_{j}$ for $1 \leq j \leq 3$ then the $j$ th element of $\tilde{G}$ is 1 and all other elements are 0 . We also assume a multinomial logit model for the activity $A$,

$$
\operatorname{Pr}(A=a \mid S=s, G=g, X=x)=\frac{\exp \left(\gamma_{a}+x^{\prime} \delta_{a}+\tilde{g}^{\prime} \pi_{a}+\zeta_{a g}^{\prime} \tilde{s}\right)}{\sum_{j=1}^{K_{a}} \exp \left(\gamma_{j}+x^{\prime} \delta_{j}+\tilde{g}^{\prime} \pi_{j}+\zeta_{j g}^{\prime} \tilde{s}\right)},
$$

where $\tilde{S}$ is a vector of zeros and a single one indicating the observed support category for the family. That is, if $S=s_{j}$ for $1 \leq j \leq K_{s}$ then the $j$ th element of $\tilde{S}$ is 1 and all other elements are 0 . Note that the coefficients $\zeta_{a g}$ on the support variable are specific not 
only to the activity, but also to the family's socioeconomic circumstances. That is, the support variable is interacted with the degree of socioeconomic disadvantage the family experienced while the youth was growing up.

\section{Data: The Youth in Focus Survey}

The data used in this research come from the Youth in Focus (YIF) Project. ${ }^{5}$ The YIF data are unique in combining survey data for a birth cohort of young Australians and their mothers with historical administrative data on the public benefits families received while young people were growing up. Coverage of the administrative data begins when the young people were approximately three years of age, while the survey data provide detailed information about youths' and mothers' current situation and activities as well as retrospective information on events which occurred during youths' childhoods. ${ }^{6}$ In this section, we discuss the data construction and analysis sample in more detail and introduce a measure of the family's history of socioeconomic disadvantage.

\subsection{Data Construction and Estimation Sample}

The YIF Project uses Centrelink administrative records to identify all young people born in the six-month period between October 1, 1987 and March 31, 1988 who ever had contact (directly or indirectly) with the Australian public-benefits system between January, 1991 and March, 2005 (inclusive). These administrative records contain high-quality, fortnightly information on the incidence of payments for all Australians who received a wide range of government benefits. The range of benefits include welfare payments to the unemployed, the disabled, and low-income parents etc. as well as payments which the Australian government does not consider to be "welfare" such as the Family Tax Benefit and the Child Care Benefit. ${ }^{7}$ Although young people can appear in the administrative

\footnotetext{
${ }^{5}$ For more information about the project and data see http://youthinfocus.anu.edu.au and Breunig et al. (2009).

${ }^{6}$ Data from mothers are not used in this analysis.

${ }^{7}$ Note that the Child Care Benefit is not means tested and that only families in the top 20 percent of the income distribution are ineligible for the Family Tax Benefit. To place these payments in context, similar benefits in the United States are provided to families through the tax system in the form of
} 
data if they have received public benefits themselves, most enter the system because a family member (usually a parent) received a payment which depended in part on the youth's relationship to the payee. Many families received welfare at some point in this period, however, approximately 40 percent of families did not. These families appear in the administrative data only because they received either Family Tax Benefits, Child Care Benefits or one of the precursors of these programs. The generosity of the Australian public-benefits system implies that nearly all of the young people in our birth cohort appear in the administrative data at some point during the period. ${ }^{8}$

The administrative data were used to stratify youths into one of six groups depending on the timing and the intensity of the family's welfare receipt. A stratified random sample of youths was then selected from the administrative data for interview in 2006. The contact information in the administrative data was very old for a significant proportion of sample, and it was not possible to locate many of the selected individuals. Overall, the response rate for youths was 37.2 percent. However, Homel et al. (2012) compare a series of socio-economic disadvantage, educational achievement, and employment measures constructed from YIF, Australian Census, and Longitudinal Surveys of Australian Youth (LSAY) data. They conclude that school completion rates, enrolment patterns, and experiences of disadvantage are broadly consistent across these alternative data sources. ${ }^{9}$ Data from phone interviews with the youths as well as a self-completion questionnaire were then linked to the administrative data. Youths were re-interviewed again in Wave 2 in 2008.

The achieved number of interviews was 4079 in Wave 1 and 2362 in Wave 2. For simplicity, we will refer to the youths as 18-year-olds in Wave 1 and as 20-year-olds in Wave 2. ${ }^{10}$ In constructing our estimation samples, we necessarily drop a number of standard deductions for dependent children and child care rebates.

${ }^{8}$ Comparing the YIF youth sample with Australian Census data suggests that the administrative data capture about 98 percent of the youths born in the period (Breunig et al., 2009).

${ }^{9}$ Following best practice (see Groves et al., 2004), approach letters, incentive payments, repeated callbacks, and CATI were all used to maximize response rates. More than 96 percent of young people completing the survey consented to having this information linked to their families' administrative publicbenefits records.

${ }^{10}$ At the time of their Wave 1 interviews 92 percent of youths were 18 years of age, while 4 percent had turned 19 and the remaining 4 percent had unknown ages. At the time of the Wave 2 interview, 76 percent of youths were aged 20 and 21 percent were aged 21 with 3 percent having unknown ages. 
observations due to item nonresponse. We also drop anyone who is attending secondary school at the time of the interview.

\subsection{Socioeconomic Disadvantage}

Although parental income, education, or occupation is commonly used as a proxy for socioeconomic status (e.g. D'Addio, 2007), our summary measure of the family's socioeconomic disadvantage is derived from the family's history of welfare receipt. As explained in the Introduction, the receipt of welfare payments reflects not only (temporary or persistent) poverty, but also broader social circumstances such as unemployment, family breakdown, single parenthood, disability etc. The literature on the determinants of children's cognitive achievements shows that parents' investments are important and that effects are cumulative (e.g. Todd and Wolpin, 2003, 2007; Cunha and Heckman, 2008; Cunha et al., 2010). Our measure of the disadvantage reflects the extent of the family's receipt of income-support and can be interpreted as a proxy for parents' lack of resources, among other things. ${ }^{11}$ Specifically, we identify three groups of young people as follows: those from families with no history of welfare receipt while the youth was growing up, those from families receiving welfare in less than six years, and those from families that received welfare for six or more years. For simplicity, we refer to these youths as having experienced no disadvantage ("No"), moderate disadvantage ("Mod") and extensive disadvantage ("Ext"), respectively.

Table 1 describes the relationship between the degree of socioeconomic disadvantage that families have experienced and the support that they are currently providing to their young-adult children. ${ }^{12}$ We are particularly interested in both the financial gifts young people receive from their parents as well as support that comes in the form of

\footnotetext{
${ }^{11}$ Note that the YIF administrative data contain the incidence, but not the amounts of income support receipt.

${ }^{12}$ The YIF survey asks youths to report about financial transfers received from their parents and "anyone else". For simplicity we refer to these amounts as "parental" support. Youths are also asked if they are expected to pay back any of this money, and we disregard the entire amount if they answered yes to this question. In an earlier version, we considered the entire amount a loan if they answer yes to this question, and we distinguished between receiving gifts, receiving loans and not receiving financial support (Cobb-Clark and Gørgens, 2012). Likelihood-ratio tests indicated that separately identifying financial loans from no financial support did not improve the overall fit of the model of youth activities.
} 
co-residence. ${ }^{13}$ Our results suggest that there is a strong association between socioeconomic disadvantage and family support for young adults. Higher levels of socioeconomic disadvantage are associated with an increased tendency for young people to be living independently and not receiving financial gifts from their families at age 18. Fully 19.5 percent of those young people growing up in extensive disadvantage live independently and receive no money gifts from their parents, for example, which is true of only 5.5 percent of their peers experiencing no socioeconomic disadvantage. Overall, those growing up in extensive disadvantage are almost twice as likely as those experiencing no disadvantage (26.0 versus 14.2 percent) to be living independently of their parents at age 18, and almost two thirds (63.9 percent) of disadvantaged 18-year-olds receive no financial gifts from their parents. Gift amounts for those who receive them are also lower, the more disadvantaged families are.

\section{[Insert Table 1 about here]}

Not surprisingly, there is a clear progression towards increased independence between the ages of 18 and 20. Irrespective of their socioeconomic background, young adults are increasingly likely to be living independently and supporting themselves. Still, the relative effects of family circumstances continue to be apparent. Growing up in a family with a long history of welfare receipt is associated with lower probabilities of receiving financial gifts or co-residential support from one's parents at age 20. More than three in four of disadvantaged 20-year-olds receive no financial support from their parents, and more than one in three is living independently. In comparison, about two in five of young people growing up in families with no history of welfare receipt are receiving financial gifts from their parents at age 20, and almost three in four continue to live at home.

Table 2 shows that young adults' engagement in education and employment is closely linked to their family circumstances. Those young people experiencing extensive disadvantage have high rates of disengagement with nearly one in five (17.5 percent) being

\footnotetext{
${ }^{13}$ Some young people live with relatives or other (older) adults. We determine whether they "co-reside" or "live independently" based on whether they consider any of the adults in their household a "parental figure" and on whether they consider themselves to be living independently or not.
} 
neither employed nor engaged in study at age 18. In contrast, this is true of only 4.5 percent of 18-year-olds experiencing no socioeconomic disadvantage. These differences are largely driven by the high enrollment rates (70.0 percent) of young people in relatively advantaged families relative to those in disadvantaged families (48.2 percent). The prevalence of part-time work among students is also markedly higher for advantaged youths. In contrast, the full-time employment rates of 18-year-olds varies much less by family circumstances.

\section{[Insert Table 2 about here]}

By age 20, the disparity in enrollment rates has narrowed somewhat suggesting that disadvantaged young people may be delaying rather than abandoning further study. Still, it remains the case that there is a persistent relationship between family circumstances and the engagement of young people in either education or employment.

\section{Results}

Our goal is twofold. First, we assess whether or not young people who grow up in socioeconomic disadvantage receive less financial and co-residential support from their parents. Second, we investigate the link between parental support and young people's propensity to be studying or working, paying particular attention to how this relationship varies with socioeconomic disadvantage. We address these issues by estimating multinomial logit models of the parental support that young people receive (Section 5.1) and, conditional on that support, young people's participation in education and the labor market (Section 5.2).

Our models include a range of control variables which have been chosen so as to capture both youths' potential to engage in education or employment as well as their family resources. These controls allow us to assess whether the overall (unconditional) relationship between socioeconomic disadvantage, parental support and youth activities described in Section 4.2 remains after we account for the other ways that families differ from one 
another. Specifically, we control for sex, birth year, age (linearly in months), state of residence, highest level of school completed, health status (fair/poor versus better), whether health limits amount of work, family structure history, whether the mother/father was born overseas, mother's/father's level of education (at age 14), whether the mother/father was employed (at age 14), the mother's/father's occupation (at age 14) measured using the ANU4 Status Scale. The exact list of covariates and their means are given in Appendix Table A1. Full estimation results are also presented in the appendix tables.

\subsection{Socioeconomic Disadvantage and Parental Support}

Does the co-residential and financial support that young people receive from their parents depend on their socioeconomic backgrounds? We answer this question by estimating a multinomial logit model of the four possible combinations of co-residential support and financial gift receipt. To facilitate interpretation, we present and discuss estimated probability distributions for each category of socioeconomic circumstances evaluated at the overall (weighted) sample mean of other covariates. These distributions correspond to the expected outcomes for a young person with "average" (observed) characteristics. The marginal effect of being in alternative categories of socioeconomic circumstances can be derived by taking differences in the results between the rows within each panel. This effectively highlights the disparity in the likelihood of receiving parental support among young people with "average" characteristics who grow up in different family circumstances. The top panel of Table 3 presents results for 18 year-olds just completing secondary school (i.e. Wave 1), while the bottom panel of the table presents results for Wave 2 when young people are 20 years of age.

\section{[Insert Table 3 about here]}

Young adults are more likely to be fully independent, i.e. not co-residing nor receiving gifts, the more disadvantaged their families are. In particular, the typical 18 year-old has an 11.3 percent probability of living independently and not receiving gifts from his parents if his family received extensive welfare benefits. Moderate (as opposed to extensive) 
welfare receipt reduces this probability by 2.1 percentage points (to 9.2 percent), while the absence of any welfare receipt is associated with a 4.9 percentage point reduction (to 6.4 percent) in the probability of being fully independent of one's parents.

Financial gifts are more closely linked to families' socioeconomic disadvantage than is co-residence. More precisely, the socioeconomic gradient is somewhat steeper for financial gifts than it is for co-residence. An 18 year-old has a probability of co-residing (whether or not he receives gifts), for example, which ranges from 85.5 percent if his family has no welfare history to 82.2 if his family received extensive welfare assistance. In contrast, the probability of receiving gifts (irrespective of co-residence status) ranges more widely from 46.5 percent (no welfare receipt) to 40.8 percent (extensive welfare receipt).

That socioeconomic disadvantage constrains the receipt of financial gifts more than co-residence is consistent with the nonrival (public) nature of housing and the rival (private) nature of financial gifts. Parents wishing to support their young-adult children will typically find it less expensive to do so through co-residence than through direct financial gifts. Kaplan (2010) argues that the option to move in and out of the parental home is a particularly valuable insurance mechanism for youths from poor families precisely because their families would struggle to provide financial assistance in the event they need help. Our results suggest, however, that the option to co-reside may also be more limited for disadvantaged youths.

The receipt of parental support as young people enter their early 20s continues to be closely linked to their families' socioeconomic circumstances while they were growing up. The absolute disparities associated with socioeconomic disadvantage are, in many cases, even larger at age 20 than at age 18, though the proportional differences are often smaller. For example, receiving extensive as opposed to no welfare assistance while young is associated with a 7.4 percentage point increase in the probability that the typical 20 year-old lives independently and does not receive gifts in comparison to a 4.9 percentage point increase at age 18 .

Not surprisingly, young people are more likely to live independently of their parents at age 20 than they were at age 18 irrespective of their families' socioeconomic circumstances. 
Young people leave home earlier, however, if their families were supported by the welfare system while they were growing up. Specifically, the probability that a 20 year-old is living with his parents is 68.1 percent if his family received extensive welfare assistance — down from 82.2 percent at age 18. This represents a 14.1 percentage point decrease in the likelihood of intergenerational co-residence. In contrast, the chances of living at home is 11.3 percentage points lower ( 85.5 versus 74.2 percent) at age 20 than at age 18 if the family has never been on the welfare rolls. These trends imply that the socioeconomic gradient in co-residence is steeper at age 20 than at age 18 .

Similarly, receiving financial gifts is also more closely tied to one's family circumstances at age 20 than at age 18 . About a third (33.8 percent) of 20 year-olds in families with no welfare history receive gifts from their parents. This is true, however, of just over one quarter (27.1 percent) of 20 year-olds in families with extensive welfare experience. The difference is (absolutely and proportionately) greater than that among 18 year-olds and greater than the difference in co-residence. The steepening of the socioeconomic gradient between waves is consistent with parental support becoming more "optional", and therefore, resource constraints becoming more binding, as young people age. At the same time, Aquilino (2005) finds that parents believe they have more obligation to help their adult children out of financial difficulty than is true for their co-residing adolescent children. Thus, it may be a lack of resources, rather than a lack of willingness, which leads disadvantaged families to provide less financial support relative to more advantaged families as youths become older.

Thus, the patterns are qualitatively similar to those in the unconditional estimates discussed in Section 4.2, although the differences across age and socioeconomic circumstances are smaller when we control for the young person's characteristics and family background. Taken together, our results demonstrate that there is a negative relationship between a family's welfare history and the support parents provide to young-adult children as they complete their education and enter the labor market. Young people growing up in disadvantage are substantially more likely to be residentially and financially independent of their parents than are their peers growing up in more advantaged circumstances. This 
is consistent with Semyonov and Lewin-Epstein (2001) who also find that parental assistance to young-adult children is also more common among Israeli families from higher socioeconomic origins.

\subsection{Youths' Engagement in Education and Employment}

Is young people's participation in education and employment related to the parental support that they receive? Does this relationship vary by the family's socioeconomic circumstances? We address these questions by estimating a multinomial logit model of the probability that young people are engaged in: (i) study and full-time work; (ii) study and part-time work; (iii) study and no work; (iv) no study and full-time work; (v) no study and part-time work; and (vi) neither study nor work.

We condition our estimates on the parental support that young people receive as well as other control variables as discussed above. As explained in Section 3, we fully recognize that parental support and youth outcomes are likely to be jointly determined. Accordingly, we do not interpret the estimated effects of parental support on youth activities as causal, although we do speculate on what causal mechanisms are likely to be driving the observed associations. In Section 5.2.1, we discuss the relationship between parental support, youth outcomes and socioeconomic circumstances. In Section 5.2.2, we focus on the socioeconomic gradient in youth outcomes.

\subsubsection{How does parental support matter?}

To what extent are the outcomes of young people related to the residential and financial support they are able to garner from their parents? Is a relative lack of parental support associated with a lower propensity to be engaged in education or employment? To address these questions, we begin by calculating estimated probability distributions evaluated at the overall sample mean. We then use these probability distributions to make three broad comparisons. First, we compare the outcomes of youths who do and do not receive gifts taking into account whether they co-reside. Second, we compare the outcomes of coresiding and independent youths taking into account whether they receive financial gifts. 
Finally, we compare the outcomes of youths who receive both residential support and financial gifts (i.e. full support) with those who receive neither. In order to focus our discussion, we concentrate on the youths' overall study and employment rates.

At Age 18: The first two left-hand side panels of Table 4 show that receiving financial gifts from one's parents is associated with 18 year-olds studying more and working less whether or not they are living with their parents. ${ }^{14}$ This pattern is nearly identical for all young people though the difference is often larger for youths living apart from their parents. Socioeconomic disadvantage is typically associated with greater disparity in the study rates of those who do and do not receive gifts, but with smaller differences in full-time and nonemployment rates. For example, extensively disadvantaged 18 year-olds receiving gifts have study rates that are 10.1 percentage points higher if they live at home and 16.9 percentage points higher if they do not, relative to similarly disadvantaged youths who do not receive financial gifts. Financial gifts are associated with much less disparity in study rates of advantaged youths.

The disparity in employment rates linked to financial gifts is largest for youths growing up in families with no welfare history. In particular, advantaged youths living independently are much less likely to be working full-time (22.1 percentage points) and much more likely to be not employed (18.5 percentage points) if they receive financial gifts than if they do not. In contrast, the employment rates of extensively disadvantaged youth vary much less by whether they are receiving financial gifts from their parents. Thus, financial gifts are relatively more important in understanding which extensively disadvantaged 18 year-olds are studying and which advantaged 18 year-olds are working. One possibility is that young adults from advantaged families use gifts to increase their leisure (nonemployment) time, while youths from disadvantaged families use gifts to support themselves while studying. Or conversely, disadvantaged parents target financial gifts towards their children who are studying, while advantaged parents target financial gifts towards their children who are not working.

\section{[Insert Table 4 about here]}

\footnotetext{
${ }^{14}$ The single exception is the group who live independently and whose families received extensive welfare; they have a lower probability of not working if they receive gifts.
} 
The third and fourth panels in the left-hand side of Table 4 show that co-residence, unlike financial gifts, is associated with lower rather than higher rates of studying. ${ }^{15}$ The size of the gap does not depend much on family circumstances and is slightly larger for youths who receive financial gifts. For example, the study rate for 18 year-olds experiencing extensive disadvantage and receiving gifts is 14.7 percentage points lower if they live with their parents than if they do not; if they are not receiving gifts their study rate is 7.9 percentage points lower when co-residing. The disparity in the study rates of advantaged youths are very similar. This relationship is consistent with a story in which parental support in the form of co-residence discourages young people from studying. Alternatively, these results suggest that young people who leave home by age 18 may be doing so in order to continue their studies.

The link between co-residence and employment rates is weaker and more complex than that between co-residence and study. Living with one's parents is associated with an increase in part-time employment, and a corresponding fall in both full-time work and nonemployment, among both advantaged youths and youths experiencing moderate disadvantage. For example, advantaged 18 year-olds who do not receive gifts are 9.6 percentage points more likely to be employed part-time if they co-reside than if they live independently; if they do receive gifts they are 13.2 percentage points more likely to work part time. In contrast, the patterns for 18 year-olds experiencing extensive disadvantage differ between those who do and do not receive gifts. Specifically, living with ones parents is associated with a modest increase in nonemployment rates, at the expense of lower rates of part-time work, for those who receive gifts, while co-residence for those who do not receive gifts is associated with a large shift from not working to full-time employment.

Overall, receiving full parental support (i.e. both co-residing and receiving financial gifts) versus receiving no parental support is associated with a 6.0 percentage point fall in the chances that 18 year-olds from families with no welfare history are studying. On the other hand, full parental support is associated with an increased study rate of between 2.2 (extensive) and 14.8 (moderate) percentage points for disadvantaged youths. One

\footnotetext{
${ }^{15}$ The single exception is that 18 year-olds experiencing moderate socioeconomic disadvantage who do not receive financial gifts are more likely to be studying if they co-reside rather than live independently.
} 
possible interpretation is that advantaged parents appear to be targeting their support towards their 18 year-old children who are not studying, while parents with any welfare history provide relatively more support to their 18 year-olds who are studying.

At the same time, receiving both residential support and financial gifts is associated with lower full-time and nonemployment rates for almost all 18 year-olds. ${ }^{16}$ The link between full parental support and employment outcomes is especially strong for advantaged youths, however. In particular, full-time employment rates are 23.6 percentage points lower and nonemployment rates are 6.7 percentage points higher among advantaged 18 year-olds who both co-reside and receive gifts. In contrast, the employment rates of 18 year-olds experiencing extensive socioeconomic disadvantage depend much less on whether they are receiving full or no parental support. Thus, the labor supply decisions of advantaged young people may be relatively more responsive to whether or not they receive support from their parents. Alternatively, advantaged parents may reduce their economic support for adult children with full-time employment.

At Age 20: The relationship between parental support and youth's engagement in education and employment is somewhat different at age 20 than at age 18 . Twenty yearolds who receive financial gifts from their parents are more likely to be studying, less likely to be employed full-time, and more likely to be not employed whether or not they live with their parents. The same is true at age 18. However, these relationships are generally much stronger among 20 year-olds than among 18 year-olds. ${ }^{17}$ For example, advantaged 20 year-olds who co-reside are 10.0 percentage points more likely to be studying if they receive financial gifts than if they do not. At age 18, this differential is only 3.0 percentage points.

At age 18, co-residence is almost universally associated with a large decline in study rates, suggesting perhaps that those young people who leave home before age 18 disproportionately do so in order to begin their studies elsewhere. However, in many cases 20 year-olds are as likely to be studying whether or not they continue living with their

\footnotetext{
${ }^{16}$ The exception is young people whose families never received welfare have a higher probability of not working if they receive full support.

${ }^{17}$ Note that while some of the differences across categories of socioeconomic circumstances in Table 4 are individually statistically significant, they are not jointly significant (see Table A3).
} 
parents. Specifically, co-residing and independent 20 year-olds have study rates that are virtually identical if they are from an advantaged family and receive gifts or if they are from moderately or extensively disadvantaged families and do not receive gifts. On the other hand, co-residence is associated with study rates that are lower (6.8-7.0 percentage points) among 20-year olds with a welfare history who do receive financial gifts, but higher (7.4 percentage points) for youths with no welfare history who do not receive financial gifts. Regarding work, co-residence is associated with higher part-time employment rates, generally with both lower full-time rates and lower nonemployment rates.

On balance, the disparity in the study and employment outcomes of youths who receive full versus no parental support is much larger at age 20 than it is at age 18 . Perhaps parental support is more heavily targeted towards those 20 year-olds who are either studying, working part time, or not working at all. Moreover, it is interesting to note that these changes in support patterns are particularly important for understanding the study and employment outcomes of advantaged 20 year-olds who have no family history of welfare receipt. For example, full support is associated with a 17.4 percentage point increase in the likelihood that 20 year-olds with no welfare history are studying. In comparison, at age 18, full support was associated with a 6.0 percentage point reduction in study rates for these young people. Similarly, the reduction in full-time employment rates associated with full parental support among advantaged youths is 23.6 percentage points at age 18 and 30.6 percentage points at age 20. One possible explanation is that parents in advantaged families have moved from supporting 18 year-old nonstudents to supporting 20 year-old students and to increasingly targeting resources to young people who are not in full-time work. To a lesser degree, disadvantaged parents may also target resources to 20 year-old students who are not working full time.

Discussion: Taken together, our results point to a strong association between parental support and young people's engagement in education and employment. In particular, financial gifts are closely linked to higher study rates and lower full-time work rates. These patterns differ across families with different socioeconomic circumstances, especially at age 18, and the relationship is often stronger for advantaged than for disad- 
vantages youths. This later finding may indicate that wealthier parents have the resources necessary to target their more generous assistance toward helping young adults to make investments in education. This is consistent with previous research which demonstrates that parents use both co-residential and financial assistance to support their children's human capital investments (e.g. Rosenzweig and Wolpin, 1993; Keane and Wolpin, 2001; Martínez-Granado and Ruiz-Castillo, 2002). At age 20, the differences across socioeconomic circumstances are fewer, smaller, and jointly insignificant leaving the overall relationship between parental support and young people's educational and employment outcomes generally stronger, more consistent, and clearer than at age 18 . It is possible that the increasingly discretionary nature of educational investments and parental support, particularly co-residential support, as young people age may underlie this result.

\subsubsection{Can Parental Support Explain the Socioeconomic Gradient in Out- comes?}

These patterns raise interesting questions about what drives the differences in the educational and employment outcomes of youths who do and do not grow up in families receiving public assistance. Specifically, disadvantaged families provide less residential and financial support to their young adult children than do other families (see Table 3). To what extent do disparities in parental support explain (in a statistical sense) the association between young people's outcomes and the socioeconomic disadvantage they have experienced?

We address this question by comparing the socioeconomic gradient in outcomes across a series of predicted distributions where we hold constant an increasingly larger set of covariates constant. Specifically, we calculate average outcomes evaluated at (a) individual covariates; (b) the socioeconomic group mean of covariates; (c) the socioeconomic group mean of parental support and the overall mean of all other covariates; and (d) the overall mean of all covariates. All means are weighted. The first case corresponds to the unconditional mean outcomes given in Table 2, while the last case corresponds to the conditional results summarized in Table $4 .{ }^{18}$ The two intermediate hypothetical distri-

\footnotetext{
${ }^{18}$ There are minor differences relative to Table 2 due to dropping observations with missing values for
} 
butions are helpful in identifying the extent to which conditioning on certain covariates, in particular different levels of parental support, alters the socioeconomic gradient in expected outcomes. To illustrate, we graphically depict the results for aggregate study and employment rates in Figure 1. The full set of results is presented in Appendix Table A5.

The socioeconomic gradient in 18 year-olds' propensity to be studying is shown in the top-left panel of Figure 1. The difference in the rate of study among advantaged and extensively disadvantaged youths is fully 20.7 percentage points when we evaluate outcomes using individuals-specific covariates (specification a) and 23.5 percentage points when we evaluate using the socioeconomic group mean of covariates (specification b). This differential is reduced by half, however, when outcomes are evaluated using the overall mean of all covariates except parental support (specification c). Thus, approximately half of the socioeconomic gradient in studying at age 18 can be explained by the variation across family circumstances (i.e. welfare histories) in youths' characteristics other than the support they receive from parents (e.g. immigrant status, parental education, etc.). Removing the effects of differential parental support across socioeconomic groups by evaluating the rate of study at the overall mean of all covariates, including parental support, does little to change this finding. Thus, it does not appear that it is the link between socioeconomic disadvantage and parental support which underlies the relationship between disadvantage and studying at age 18 .

\section{[Insert Figure 1 about here]}

The top-right panel of Figure 1 shows that the socioeconomic gradient in study rates between advantaged and extensively disadvantaged youths is somewhat flatter at age 20 than at age 18 if we evaluate outcomes at either individual-specific covariates (specification a) or at the socioeconomic group mean of covariates (specification b). The socioeconomic gradient flattens further and becomes essentially zero as we evaluate study rates using overall means for any covariates other than parental support (specification c) and then for all covariates including parental support (specification d). In effect, the socioeconomic

covariates. 
gradient in studying can be completely explained by differences in the characteristics of those 20 year-olds growing up in different family circumstances.

The socioeconomic gradient in the employment rates of 18 year-olds is shown in the bottom-left panel of Figure 1. Unlike studying, the differential probability that advantaged and extensively disadvantaged 18 year-olds are employed is not explained by their characteristics. The socioeconomic gradient in employment is virtually identical whether we evaluate outcomes at individual-specific covariates (specification a) or at sample-mean covariates (specification d). Instead, the differential in employment rates stems either from differences in the labor supply behavior of 18 year-olds in different family circumstances with otherwise similar characteristics or from differences in the hiring behavior of employers.

In contrast, the bottom-right panel of Figure 1 shows that the socioeconomic gradient in the employment rates of 20 year-olds is flatter (10.1 versus 17.3 percentage points) and more closely linked to disparity in the characteristics of young people than was the case at age 18. Specifically, the socioeconomic gradient is much the same whether we evaluate expected employment outcomes at either individual-specific covariates (specification a) or the socioeconomic group mean of covariates (specification b), but falls substantially when we remove the effect of differences in covariates other than parental support (specification c). Accounting for the disparities in parental support has little additional effect on the socioeconomic gradient in employment rates (specification d).

Taken together, these results provide no evidence that a lack of parental support explains the socioeconomic gradient in either studying or employment among young people. In most cases, the socioeconomic gradient is substantially reduced, or effectively eliminated, once differences in characteristics other than parental support are accounted for. The exception is the socioeconomic gradient in employment at age 18 which is driven by the differential propensity of advantaged and disadvantaged young people with the same characteristics to be employed. ${ }^{19}$

\footnotetext{
${ }^{19}$ As mentioned earlier, the specification tests in Table A3 show that the coefficients representing socioeconomic circumstances are not jointly statistically significant in the model for study and employment outcomes at age 20. The results discussed in this section concern a different metric, namely predicted outcomes, and confirms that socioeconomic circumstances play a limited role.
} 


\section{Concluding Remarks}

Parents' economic support can be important in insuring young people against economic downturns (or relationship breakdowns), reducing any negative effects of credit constraints, and generally expanding the resources available to them as they complete their education and enter the labor market. Family circumstances, however, may dictate both the ability and the willingness of parents to continue supporting their children after they reach adulthood. Our results provide evidence that young people who experience socioeconomic disadvantage while growing up receive less co-residential and financial support from their parents than do their more advantaged peers. Moreover, there is a strong association between a young person's engagement in study and work and the parental support that he or she receives. Fortunately, however, we find no evidence the socioeconomic gradient in studying and employment stems from this lack of parental support.

These result are useful in highlighting the relationship between a family's socioeconomic circumstances and the economic support that parents provide to their young-adult children. At the same time, they leave a number of issues unresolved. First, our analysis has focused on the receipt, rather than the amount, of economic support that young people receive. This focus on the extensive support margin is sensible given the relatively small variation in the amount of financial support in our data and the inherent difficulty in placing a dollar value on co-residential support. It is less than ideal, however, given the evidence that the nature of the parental home influences young people's propensity to move out (e.g. Laferrère and Bessière, 2003). It would also be useful to know more about the extent to which young people's outcomes depend on the degree and type of support they receive.

Second, we can only speculate about the extent to which the socioeconomic gradient we observe in parental support stems from disparity in families' ability, rather than in their willingness, to provide economic support. In particular, the previous literature clearly demonstrates that co-residential and financial support is tied to family income and wealth (see Schoeni, 1997, for a review) suggesting that resource constraints must matter. At the same time, Aquilino (2005) finds that parents' financial resources (i.e. income, savings, 
nonmortgage debts) are not significantly related to their perceived financial obligations to their young-adult children. Nontraditional (i.e. step- and blended) families believe they need to provide less support to their young-adult children even after controlling for their differential resources. Thus, it is unclear whether the issue is resource constraints or differential preferences.

Finally, it would be useful to know more about the dynamics of parents' economic support and the role of public policy. Why do co-residence and financial gifts become more important for understanding outcomes as young people, and particularly advantaged young people, age? Does this indicate that families with resources may be increasingly directing their support to young people making investments in education or with limited ability to support themselves (see e.g. Card and Lemieux, 2000; Keane and Wolpin, 2001; Rosenzweig and Wolpin, 1993; Martínez-Granado and Ruiz-Castillo, 2002). To what extent are disadvantaged youths' able to seek out alternative forms of support?

Addressing these issues is an important next step in understanding the role of the family in supporting young people's investments in education and work.

\section{References}

Aquilino, W. S. (2005). Impact of family structure on parental attitudes toward the economic support of adult children over the transition to adulthood. Journal of Family Issues 26, 143-167.

Bernheim, B. D., A. Schleifer, and L. F. Summers (1985). The strategic bequest motive. Journal of Political Economy 93, 1045-1076.

Breunig, R., D. Cobb-Clark, T. Gørgens, C. Ryan, and A. Sartbayeva (2009). User's guide to the Youth in Focus data version 2.0. Youth in Focus Project Discussion Paper 8, Australian National University.

Card, D. and T. Lemieux (2000). Adapting to circumstances: The evolution of work, school and living arrangements among North American youth. In D. G. Blanchflower and R. B. Freeman (Eds.), Youth Employment and Joblessness in Advanced Countries, pp. 171-214. National Bureau of Economic Research, Inc. 
Cobb-Clark, D. and T. Gørgens (2012). Parents' economic support of young-adult children: Do socioeconomic circumstances matter? Youth in Focus Project Discussion Paper Series 12, Australian National University.

Cobb-Clark, D. A. (2008). Leaving home: What economics has to say about the living arrangements of young Australians. Australian Economics Review 41(2), 160-176.

Cox, D. (1987). Motives for private income transfers. Journal of Political Economy 95, $508-546$.

Cox, D. (1990). Intergenerational transfers and liquidity constraints. Quarterly Journal of Economics 105(1), 187-217.

Cox, D. and G. Jakubson (1995). The connection between public transfers and private interfamily transfers. Journal of Public Economics 57, 129-167.

Cunha, F. and J. J. Heckman (2008). Formulating, identifying and estimating the technology of cognitive and noncognitive skill formation. Journal of Human Resources 63(4), $738-782$.

Cunha, F., J. J. Heckman, and S. Schennach (2010). Estimating the technology of cognitive and noncognitive skill formation. Econometrica 78(3), 883-931.

D'Addio, A. C. (2007). Intergenerational transmission of disadvantage: Mobility or immobility across generations? A review of the evidence for OECD countries. OECD Social, Employment and Migration Working Papers 52, OECD Publishing.

Dimova, R. and F.-C. Wolff (2010). Do downward private transfers enhance maternal labor supply? Evidence from around Europe. Journal of Population Economics 24(3), $911-933$.

Dustmann, C., J. Micklewright, and A. van Soest (2009). In-school labour supply, parental transfers, and wages. Empirical Economics 37, 201-218.

Ermisch, J. (1999). Prices, parents, and young people's household formation. Journal of Urban Economics 7, 137-207.

Ermisch, J. (2003). An Economic Analysis of the Family. Princeton, New Jersey: Princeton University Press.

Ermisch, J. and P. Di Salvo (1997). The economic determinants of young people's house- 
hold formation. Economica 64, 627-644.

Folgi, A. (2000). Endogenous labour market rigidites and family ties. Working paper, New York University.

Goldscheider, F., A. Thornton, and L.-S. Yang (2001). Helping out the kids: Expectations about parental support in young adulthood. Journal of Marriage and Family 63(3), $727-740$.

Gong, T. (2009). Do parental transfers reduce youths' incentives to work? Labour 23(4), 654-676.

Groves, R. M., F. J. Fowler, M. P. Couper, J. M. Lepkowski, E. Singer, and R. Tourangeau (2004). Survey Methodology. New Jersey, USA: Wiley-Interscience.

Guiso, L. and T. Jappelli (2002). Private transfers, borrowing constraints, and the timing of homeownership. Journal of Money, Credit, and Banking 34, 315-339.

Hamon, R. R. (1995). Parents as resources when adult children divorce. Journal of Divorce and Remarriage 23, 171-184.

Hao, L., J. Hotz, and G. Z. Jin (2008). Games parents and adolescents play: Risky behaviour, parental reputation and strategic transfers. Economic Journal 118, 515555.

Homel, J., A. Mavisakalyan, H. T. Nguyen, and C. Ryan (2012). School completion: What we learn from different measures of family background. Longitudinal Surveys of Australian Youth Research report 59, NCVER.

Kalenkoski, C. (2008). Parent-child bargaining, parental transfers, and the post-secondary education decision. Applied Economics 40, 413-436.

Kalenkoski, C. M. and S. W. Pabilonia (2010). Parental transfers, student achievement, and the labor supply of college students. Journal of Population Economics 23, 469-496.

Kaplan, G. (2010). Moving back home: Insurance against labor market risk. Journal of Political Economy 120(3), 446-512.

Keane, M. P. and K. I. Wolpin (2001). The effect of parental transfers and borrowing constraints on education attainment. International Economic Review 42(4), 1051-1103.

Kooreman, P. (2004). Time, money, peers, and parents: Some data and theories on child 
behavior. Journal of Population Economics 20, 9-33.

Laferrère, A. (2006). Leaving the nest: Parental income, housing, and altruism. Unpublished manuscript.

Laferrère, A. and S. Bessière (2003). Nest-living and nest-leaving: Does the nest matter? Unpublished working paper.

Le Blanc, D. and F.-C. Wolff (2006). Leaving home in Europe: The role of parents' and children's incomes. Review of Economics of the Household 4, 53-73.

Lundberg, S., J. L. Romich, and K. P. Tsang (2007). Decision-making by children. Review of Economics of the Household 1(1), 1-30.

Manacorda, M. and E. Moretti (2006). Why do most Italian youths live with their parents? intergenerational transfers and household structure. Journal of the European Economic Association 4(4), 800-829.

Martínez-Granado, M. and J. Ruiz-Castillo (2002). The decisions of Spanish youth: A cross-section study. Journal of Population Economics 15, 305-330.

McElroy, M. B. (1985). The joint determination of household membership and market work: The case of young men. Journal of Labor Economics 3(3), 293-316.

Oettinger, G. S. (2005). Parents' financial support, students' employment and academic performance in college. Working paper, University of Texas.

Pabilonia, S. W. (2001). Evidence on youth employment, earnings and parental transfers in the national longitudinal survey of youth 1997. Journal of Human Resources 36(4), $795-822$.

Pollak, R. A. (1988). Tied transfers and paternalistic preferences. American Economic Review 78(2), 240-244.

Rosenzweig, M. R. and K. I. Wolpin (1993). Intergenerational support and the life-cycle incomes of young men and their parents: Human capital investments, coresidence, and intergenerational financial transfers. Journal of Labor Economics 11(1), 84-112.

Schoeni, R. F. (1997). Private interhousehold transfers of money and time: New empirical evidence. Review of Income and Wealth 43(4), 423-448.

Semyonov, M. and N. Lewin-Epstein (2001). The impact of parental transfers on living 
standards of married children. Social Indicators Research 54(2), 115-137.

Todd, P. E. and K. I. Wolpin (2003). On the specification and estimation of the production function for cognitive achievement. Economic Journal 113, F3-F33.

Todd, P. E. and K. I. Wolpin (2007). The production of cognitive achievement in children: Home, school, and racial test score gaps. Journal of Human Capital 1(1), 91-136.

Weinberg, B. A. (2001). An incentive model of the effect of parental income on children. Journal of Political Economy 109(2), 266-280.

Wolf, D. A. and B. J. Soldo (1989). Household composition choices of older unmarried women. Demography 25(3), 387-404.

Wolff, F.-C. (2006). Parental transfers and the labor supply of children. Journal of Population Economics 19, 853-877. 
Table 1: Co-residence and Financial Assistance by Socioeconomic Circumstances

No Mod Ext

Wave 1 (age 18)

Co-residence and financial assistance (percent distribution by column)

Co-residence and gift

$41.7 \quad 34.8$

29.5

Co-residence and no gift

$44.1 \quad 46.6$

44.4

Independent and no gift

$\begin{array}{lll}5.5 & 11.1 \quad 19.5\end{array}$

Independent and gift

$8.6 \quad 7.5$

6.6

Subtotals (percent)

Co-residence

$85.8 \quad 81.4 \quad 74.0$

Gift

$50.4 \quad 42.4 \quad 36.1$

Gift amount received excluding zeros (dollars)

Median

$2000 \quad 1200 \quad 1000$

90th percentile

$10000 \quad 10000 \quad 6208$

Wave 2 (age 20)

Co-residence and financial assistance (percent distribution by column)

Co-residence and gift

$29.6 \quad 20.2$

16.2

Co-residence and no gift

$44.5 \quad 48.5 \quad 46.5$

Independent and no gift

$15.0 \quad 21.1 \quad 30.2$

Independent and gift

$10.9 \quad 10.2$

7.1

Subtotals (percent)

Co-residence

$\begin{array}{lll}74.1 & 68.7 & 62.8\end{array}$

Gift

$\begin{array}{lll}40.5 & 30.4 & 23.3\end{array}$

Gift amount received excluding zeros (dollars)

Median

$2780 \quad 1153 \quad 1000$

90th percentile

$12000 \quad 10000 \quad 8000$

No, Mod, Ext: no, moderate, and extensive socioeconomic disadvantage. Source: Youth in Focus Survey data. Sample restricted to respondents who are not in school and have nonmissing values for parental support and youth outcomes. Weighted estimates; weights not adjusted for sample restrictions. 
Table 2: Educational and Employment Outcomes by Socioeconomic Circumstances

No Mod Ext

Wave 1 (age 18)

Educational and employment outcomes (percent distribution by column)

Study, full-time work

Study, part-time work

Study, no work

No study, full-time work

No study, part-time work

No study, no work
18.0

40.9

11.1

13.4

12.1

4.5

Educational outcomes (percent distribution by column)

Study

No study

70.0

30.0
20.3

27.7

13.2

16.8

13.9

8.1

61.2

38.8

48.2

51.8

Employment outcomes (percent distribution by column)

Full-time work

31.4

53.0

37.1

33.1

Part-time work

$15.6 \quad 21.3$

14.8

17.8

15.6

18.3

16.0

17.5

No work

Wave 2 (age 20)

Educational and employment outcomes (percent distribution by column)

Study, full-time work

Study, part-time work

Study, no work

No study, full-time work

No study, part-time work

No study, no work
16.3

41.0

11.1

18.1

9.1

4.4
17.5

28.7

10.5

25.3

11.2

6.8

56.8

$31.5 \quad 43.2$

53.7

46.3

Study

Employment outcomes (percent distribution by column)

Full-time work

34.4

42.8

50.1

39.9

15.6
15.0

24.1

14.6

23.0

11.2

12.1
17.3

38.0

35.3

No work

No, Mod, Ext: no, moderate, and extensive socioeconomic disadvantage. Source: Youth in Focus Survey data. Sample restricted to respondents who are not in school and have nonmissing values for parental support and youth outcomes. Weighted estimates; weights not adjusted for sample restrictions. Part-time work includes respondents with unknown hours. 
Table 3: Predicted Parental Support

\begin{tabular}{lrrrrrr}
\hline & \multicolumn{7}{c}{ Co-residing } & \multicolumn{2}{c}{ Independent } & Total & Total \\
& Gift & No gift & No gift & Gift & Cores & Gift \\
\hline \multirow{7}{*}{ No disadv } & & Wave 1 & (age 18) & & \\
& 38.4 & 47.1 & 6.4 & 8.1 & 85.5 & 46.5 \\
Mod disadv & 1.8 & 1.9 & 0.9 & 1.0 & 1.4 & 1.7 \\
& 34.7 & 49.2 & 9.2 & 6.9 & 83.9 & 41.7 \\
Ext disadv & 1.4 & 1.5 & 0.8 & 0.7 & 1.1 & 1.4 \\
& 34.2 & 47.9 & 11.3 & 6.5 & 82.2 & 40.8 \\
& 1.8 & 1.8 & 1.1 & 0.9 & 1.6 & 1.9 \\
& & & & & & \\
No disadv & 24.5 & 49.7 & 16.5 & 9.3 & 74.2 & 33.8 \\
& 2.0 & 2.5 & 1.9 & 1.2 & 2.2 & 2.1 \\
Mod disadv & 19.5 & 51.6 & 19.5 & 9.4 & 71.1 & 28.9 \\
& 1.7 & 1.8 & 1.5 & 1.2 & 1.6 & 1.8 \\
Ext disadv & 19.1 & 49.0 & 23.9 & 8.0 & 68.1 & 27.1 \\
& 2.0 & 2.6 & 2.3 & 1.2 & 2.5 & 2.2 \\
\hline
\end{tabular}

Gift, No gift: receiving financial assistance in the form of gifts or not; Cores: coresiding; No, Mod, Ext disadv: no, moderate and extensive socioeconomic disadvantage. Standard errors in italics (nonparametric bootstrap with fixed evaluation points). Source: Youth in Focus Survey data. Sample restricted to respondents who are not in school and have nonmissing values for parental support, youth outcomes and all covariates. Predictions based on multinomial logit models with six categories of parental support evaluated at overall weighted sample means, see Tables A1 and A2. 
Table 4: Comparisons of Predicted Educational and Employment Outcomes

\begin{tabular}{lrrrrrrrr}
\hline & \multicolumn{3}{c}{ Wave 1 (age 18) } & \multicolumn{5}{c}{ Wave 2 (age 20) } \\
& Stdy & FtW & PtW & NoW & Stdy & FtW & PtW & NoW \\
\hline \multirow{2}{*}{ The effect of receiving financial gifts } & (gift versus no & gift) & if co-residing \\
No disadv & 3.0 & -16.8 & 7.2 & 9.6 & 10.0 & -20.3 & 5.2 & 15.1 \\
& 4.0 & 4.0 & 3.8 & 3.1 & 5.4 & 5.0 & 5.3 & 4.6 \\
Mod disadv & 5.9 & -14.3 & 4.4 & 10.0 & 11.6 & -18.2 & 2.9 & 15.3 \\
& 3.5 & 3.2 & 2.9 & 2.7 & 5.0 & 5.1 & 4.9 & 3.9 \\
Ext disadv & 10.1 & -15.8 & 6.1 & 9.7 & 14.1 & -20.4 & 7.7 & 12.7 \\
& 3.9 & 3.7 & 3.9 & 3.3 & 6.6 & 5.6 & 6.3 & 5.3
\end{tabular}

The effect of receiving financial gifts (gift versus no gift) if independent

$\begin{array}{lrrrrrrrr}\text { No disadv } & 6.4 & -22.1 & 3.6 & 18.5 & 18.1 & -22.6 & 15.2 & 7.4 \\ \text { Mod disadv } & 8.8 & 9.3 & 8.5 & 8.1 & 8.7 & 9.2 & 8.2 & 7.5 \\ & 23.9 & -12.4 & 4.4 & 7.9 & 18.0 & -22.8 & 7.0 & 15.8 \\ \text { Ext disadv } & 6.0 & 7.8 & 6.5 & 6.6 & 7.2 & 6.7 & 5.8 & 6.4 \\ & 16.9 & -2.8 & 11.6 & -8.7 & 21.7 & -10.2 & -7.4 & 17.6 \\ & 6.7 & 6.4 & 7.2 & 6.2 & 6.9 & 8.3 & 7.3 & 6.5\end{array}$

The effect of co-residence (co-residing versus independent) if receiving gift

$\begin{array}{lrrrrrrrr}\text { No disadv } & -12.5 & -1.4 & 13.2 & -11.8 & -0.7 & -8.0 & 9.7 & -1.8 \\ & 5.9 & 5.7 & 6.3 & 6.3 & 7.2 & 8.3 & 7.7 & 7.5 \\ \text { Mod disadv } & -9.1 & -2.3 & 16.5 & -14.2 & -7.0 & 1.1 & 7.5 & -8.6 \\ & 5.8 & 5.9 & 5.0 & 5.3 & 7.2 & 6.8 & 6.1 & 6.9 \\ \text { Ext disadv } & -14.7 & 1.5 & -7.4 & 5.9 & -6.8 & -7.3 & 14.7 & -7.5 \\ & 5.8 & 6.2 & 6.9 & 5.9 & 8.1 & 7.3 & 7.4 & 8.3\end{array}$

The effect of co-residence (co-residing versus independent) if not receiving gift

$\begin{array}{lrrrrrrrr}\text { No disadv } & -9.0 & -6.8 & 9.6 & -2.9 & 7.4 & -10.3 & 19.8 & -9.5 \\ & 7.3 & 7.9 & 8.1 & 6.4 & 6.6 & 6.9 & 5.9 & 5.2 \\ \text { Mod disadv } & 9.0 & -0.3 & 16.6 & -16.2 & -0.6 & -3.6 & 11.7 & -8.1 \\ & 4.2 & 5.3 & 4.3 & 4.3 & 5.4 & 5.2 & 4.6 & 3.3 \\ \text { Ext disadv } & -7.9 & 14.5 & -2.0 & -12.5 & 0.7 & 2.9 & -0.4 & -2.5 \\ & 4.1 & 3.3 & 4.3 & 3.4 & 5.2 & 5.3 & 5.3 & 3.6\end{array}$

The effect of full parental support versus no support

\begin{tabular}{lrrrrrrrr} 
No disadv & -6.0 & -23.6 & 16.8 & 6.7 & 17.4 & -30.6 & 25.0 & 5.6 \\
Mod disadv & 7.3 & 8.0 & 7.7 & 6.4 & 7.3 & 7.3 & 6.1 & 6.3 \\
& 14.8 & -14.7 & 20.9 & -6.3 & 11.0 & -21.7 & 14.6 & 7.2 \\
Ext disadv & 4.1 & 5.6 & 4.6 & 4.9 & 5.7 & 6.2 & 5.8 & 5.0 \\
& 2.2 & -1.3 & 4.2 & -2.8 & 14.9 & -17.4 & 7.3 & 10.1 \\
& 5.2 & 3.6 & 4.5 & 4.5 & 7.1 & 5.8 & 6.9 & 5.3 \\
\hline
\end{tabular}

Stdy: Studying (whether working or not); FtW, PtW, NoW: full-time, part-time, and no work (whether studying or not); No, Mod, Ext disadv: no, moderate and extensive socioeconomic disadvantage. Standard errors in italics (nonparametric bootstrap with fixed evaluation points). Source: Youth in Focus Survey data. Sample restricted to respondents who are not in school and have nonmissing values for parental support, youth outcomes and all covariates. Part-time work includes respondents with unknown hours. Predictions based on multinomial logit models with six categories of educational and employment outcomes (all combinations of studying and full-time/part-time/no work) evaluated at overall weighted sample means, see Tables A1 and A4. 
Probability of studying

Wave 1 (age 18)

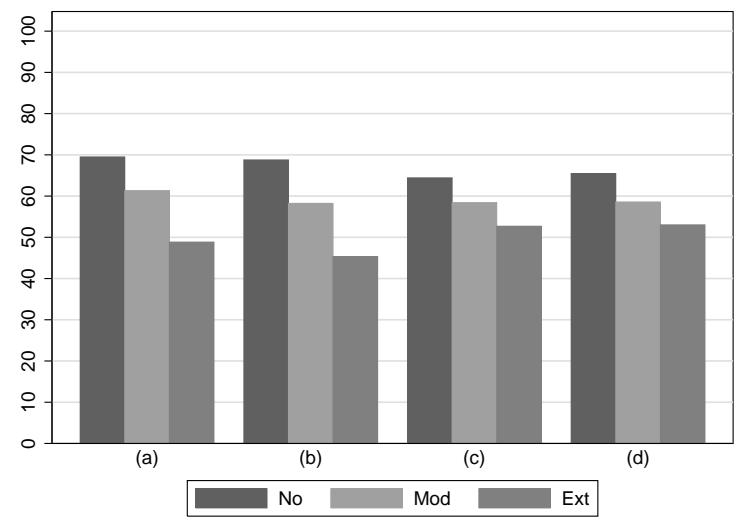

Probability of working

Wave 1 (age 18)

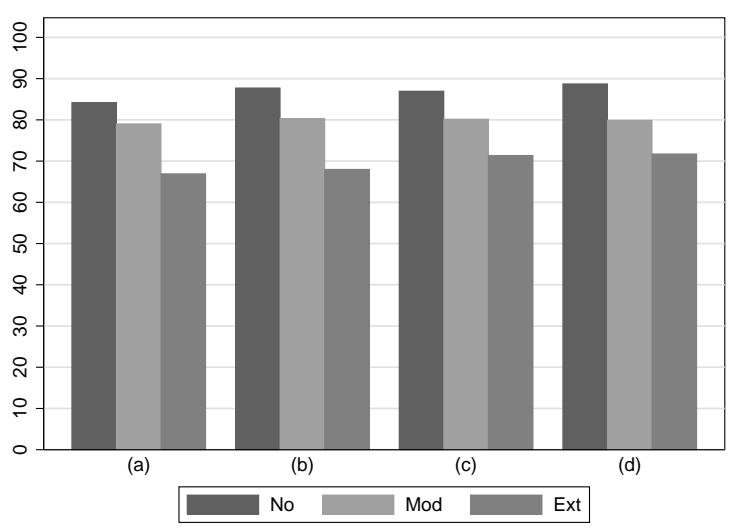

Probability of studying

Wave 2 (age 20)

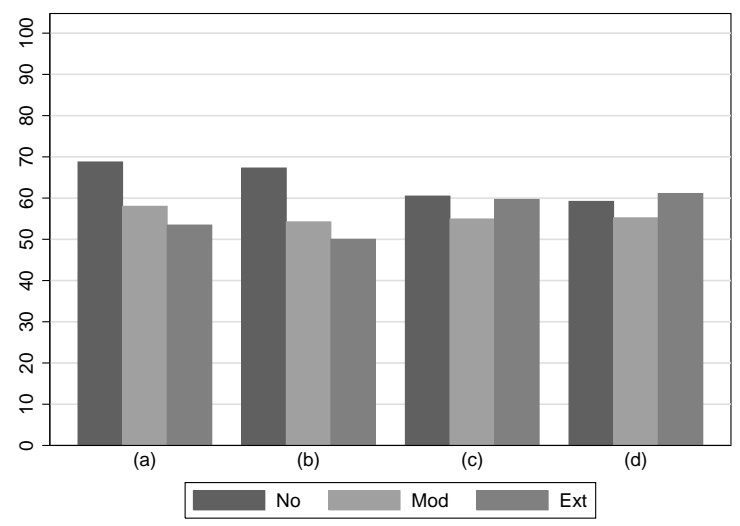

Probability of working

Wave 2 (age 20)

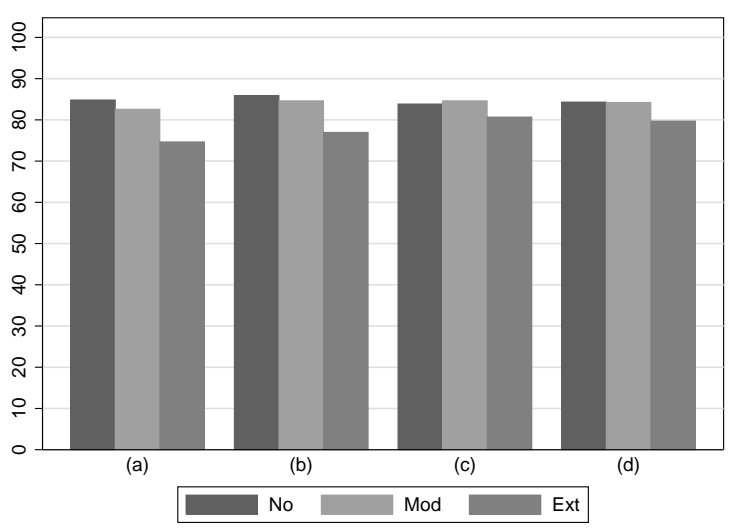

No, Mod, Ext: no, moderate, and extensive socioeconomic disadvantage; (a), (b), (c), (d): predictions evaluated at (a) observed covariates, (b) socioeconomic group means of all covariates, (c) socioeconomic group means of parental support and overall means of other covariates, (d) overall means of all covariates. Source: Youth in Focus Survey data. Sample restricted to respondents who are not in school and have nonmissing values for parental support, youth outcomes and all covariates. Part-time work includes respondents with unknown hours. Predictions based on multinomial logit models with six categories of educational and employment outcomes (all combinations of studying and full-time/part-time/no work) evaluated at weighted sample means, see Table A5.

Figure 1: Predicted Educational and Employment Outcomes 
Table A1: Covariate Means and Sample Sizes

\begin{tabular}{|c|c|c|c|c|c|c|c|c|}
\hline & \multicolumn{4}{|c|}{ Wave 1 (age 18) } & \multicolumn{4}{|c|}{ Wave 2 (age 20$)$} \\
\hline & All & No & Mod & Ext & All & No & Mod & Ext \\
\hline \multicolumn{9}{|c|}{ Socioeconomic circumstances } \\
\hline No disadv & 0.422 & 1.000 & 0.000 & 0.000 & 0.418 & 1.000 & 0.000 & 0.000 \\
\hline Mod disadv & 0.308 & 0.000 & 1.000 & 0.000 & 0.316 & 0.000 & 1.000 & 0.000 \\
\hline Ext disadv & 0.270 & 0.000 & 0.000 & 1.000 & 0.267 & 0.000 & 0.000 & 1.000 \\
\hline \multicolumn{9}{|c|}{ Parental support } \\
\hline Cores, gift & 0.365 & 0.418 & 0.349 & 0.299 & 0.229 & 0.292 & 0.201 & 0.163 \\
\hline Cores, no gift & 0.450 & 0.440 & 0.470 & 0.442 & 0.463 & 0.446 & 0.488 & 0.460 \\
\hline Indpt, no gift & 0.108 & 0.055 & 0.107 & 0.192 & 0.211 & 0.151 & 0.211 & 0.305 \\
\hline Indpt, gift & 0.078 & 0.088 & 0.074 & 0.067 & 0.097 & 0.111 & 0.100 & 0.072 \\
\hline \multicolumn{9}{|c|}{ Age (months minus 220) } \\
\hline Mean & 5.052 & 5.079 & 5.018 & 5.050 & 30.27 & 30.22 & 30.27 & 30.33 \\
\hline \multicolumn{9}{|c|}{ Highest level of school completed } \\
\hline Not Year 12 & 0.256 & 0.153 & 0.260 & 0.412 & 0.180 & 0.109 & 0.185 & 0.287 \\
\hline Year 12 & 0.744 & 0.847 & 0.740 & 0.588 & 0.820 & 0.891 & 0.815 & 0.713 \\
\hline \multicolumn{9}{|l|}{ Home state } \\
\hline $\mathrm{NSW}+\mathrm{ACT}$ & 0.324 & 0.332 & 0.314 & 0.323 & 0.323 & 0.342 & 0.301 & 0.320 \\
\hline $\mathrm{VIC}$ & 0.250 & 0.259 & 0.266 & 0.218 & 0.268 & 0.265 & 0.300 & 0.236 \\
\hline QLD & 0.213 & 0.188 & 0.225 & 0.240 & 0.204 & 0.196 & 0.209 & 0.211 \\
\hline $\mathrm{SA}$ & 0.079 & 0.084 & 0.066 & 0.086 & 0.075 & 0.074 & 0.068 & 0.083 \\
\hline $\mathrm{WA}+\mathrm{NT}$ & 0.110 & 0.118 & 0.104 & 0.103 & 0.099 & 0.101 & 0.096 & 0.100 \\
\hline TAS & 0.024 & 0.019 & 0.025 & 0.029 & 0.031 & 0.022 & 0.026 & 0.050 \\
\hline \multicolumn{9}{|c|}{ Health status fair or poor } \\
\hline No & 0.918 & 0.937 & 0.917 & 0.888 & 0.925 & 0.928 & 0.927 & 0.917 \\
\hline Yes & 0.082 & 0.063 & 0.083 & 0.112 & 0.075 & 0.072 & 0.073 & 0.083 \\
\hline \multicolumn{9}{|c|}{ Health limits amount of work } \\
\hline No & 0.934 & 0.948 & 0.931 & 0.916 & 0.930 & 0.950 & 0.931 & 0.897 \\
\hline Yes & 0.066 & 0.052 & 0.069 & 0.084 & 0.070 & 0.050 & 0.069 & 0.103 \\
\hline \multicolumn{9}{|l|}{ Sex } \\
\hline Female & 0.492 & 0.491 & 0.496 & 0.488 & 0.489 & 0.484 & 0.492 & 0.495 \\
\hline Male & 0.508 & 0.509 & 0.504 & 0.512 & 0.511 & 0.516 & 0.508 & 0.505 \\
\hline \multicolumn{9}{|l|}{ Birth year } \\
\hline 1987 & 0.518 & 0.524 & 0.517 & 0.511 & 0.489 & 0.498 & 0.484 & 0.482 \\
\hline 1988 & 0.482 & 0.476 & 0.483 & 0.489 & 0.511 & 0.502 & 0.516 & 0.518 \\
\hline
\end{tabular}

Continued next page. 


\begin{tabular}{|c|c|c|c|c|c|c|c|c|}
\hline & \multicolumn{4}{|c|}{ Wave 1 (age 18 ) } & \multicolumn{4}{|c|}{ Wave 2 (age 20$)$} \\
\hline & All & No & Mod & Ext & All & No & Mod & Ext \\
\hline \multicolumn{9}{|c|}{ Mother born overseas } \\
\hline No & 0.734 & 0.763 & 0.715 & 0.711 & 0.738 & 0.769 & 0.719 & 0.714 \\
\hline Yes & 0.266 & 0.237 & 0.285 & 0.289 & 0.262 & 0.231 & 0.281 & 0.286 \\
\hline \multicolumn{9}{|c|}{ Father born overseas } \\
\hline No & 0.710 & 0.728 & 0.697 & 0.697 & 0.701 & 0.722 & 0.690 & 0.681 \\
\hline Yes & 0.290 & 0.272 & 0.303 & 0.303 & 0.299 & 0.278 & 0.310 & 0.319 \\
\hline \multicolumn{9}{|c|}{ Ever lived with stepparent } \\
\hline No & 0.847 & 0.957 & 0.827 & 0.698 & 0.861 & 0.961 & 0.830 & 0.741 \\
\hline Yes & 0.153 & 0.043 & 0.173 & 0.302 & 0.139 & 0.039 & 0.170 & 0.259 \\
\hline \multicolumn{9}{|c|}{ Ever lived with single parent } \\
\hline No & 0.699 & 0.905 & 0.690 & 0.387 & 0.710 & 0.901 & 0.713 & 0.406 \\
\hline Yes & 0.301 & 0.095 & 0.310 & 0.613 & 0.290 & 0.099 & 0.287 & 0.594 \\
\hline \multicolumn{9}{|c|}{ Ever lived with grandparents, foster parents etc. } \\
\hline No & 0.911 & 0.966 & 0.910 & 0.826 & 0.918 & 0.965 & 0.912 & 0.851 \\
\hline Yes & 0.089 & 0.034 & 0.090 & 0.174 & 0.082 & 0.035 & 0.088 & 0.149 \\
\hline \multicolumn{9}{|c|}{ Mother completed Year 12 (age 14) } \\
\hline No & 0.522 & 0.405 & 0.558 & 0.662 & 0.496 & 0.368 & 0.546 & 0.636 \\
\hline Yes & 0.478 & 0.595 & 0.442 & 0.338 & 0.504 & 0.632 & 0.454 & 0.364 \\
\hline \multicolumn{9}{|c|}{ Mother's education (age 14) missing } \\
\hline No & 0.919 & 0.948 & 0.916 & 0.880 & 0.930 & 0.957 & 0.927 & 0.891 \\
\hline Yes & 0.081 & 0.052 & 0.084 & 0.120 & 0.070 & 0.043 & 0.073 & 0.109 \\
\hline \multicolumn{9}{|c|}{ Mother employed (age 14) } \\
\hline No & 0.314 & 0.215 & 0.304 & 0.482 & 0.320 & 0.214 & 0.316 & 0.490 \\
\hline Yes & 0.686 & 0.785 & 0.696 & 0.518 & 0.680 & 0.786 & 0.684 & 0.510 \\
\hline \multicolumn{9}{|c|}{ Mother's employment (age 14) missing } \\
\hline No & 0.969 & 0.985 & 0.969 & 0.945 & 0.973 & 0.987 & 0.976 & 0.947 \\
\hline Yes & 0.031 & 0.015 & 0.031 & 0.055 & 0.027 & 0.013 & 0.024 & 0.053 \\
\hline \multicolumn{9}{|c|}{ Mother's occupational status (age 14) } \\
\hline Mean ANU4 scale & 0.378 & 0.449 & 0.373 & 0.273 & 0.394 & 0.474 & 0.386 & 0.279 \\
\hline \multicolumn{9}{|c|}{ Mother's occupation (age 14): other } \\
\hline No & 0.986 & 0.983 & 0.989 & 0.988 & & & & \\
\hline Yes & 0.014 & 0.017 & 0.011 & 0.012 & & & & \\
\hline \multicolumn{9}{|c|}{ Mother's occupation (age 14): none or missing (wave 2 including other) } \\
\hline No & 0.938 & 0.951 & 0.938 & 0.918 & 0.820 & 0.886 & 0.833 & 0.702 \\
\hline Yes & 0.062 & 0.049 & 0.062 & 0.082 & 0.180 & 0.114 & 0.167 & 0.298 \\
\hline
\end{tabular}

Continued next page. 


\begin{tabular}{|c|c|c|c|c|c|c|c|c|}
\hline & \multicolumn{4}{|c|}{ Wave 1 (age 18 ) } & \multicolumn{4}{|c|}{ Wave 2 (age 20$)$} \\
\hline & All & No & Mod & Ext & All & No & Mod & Ext \\
\hline \multicolumn{9}{|c|}{ Father completed Year 12 (age 14) } \\
\hline No & 0.580 & 0.442 & 0.608 & 0.764 & 0.546 & 0.406 & 0.583 & 0.722 \\
\hline Yes & 0.420 & 0.558 & 0.392 & 0.236 & 0.454 & 0.594 & 0.417 & 0.278 \\
\hline \multicolumn{9}{|c|}{ Father's education (age 14) missing } \\
\hline No & 0.853 & 0.949 & 0.872 & 0.682 & 0.871 & 0.956 & 0.882 & 0.723 \\
\hline Yes & 0.147 & 0.051 & 0.128 & 0.318 & 0.129 & 0.044 & 0.118 & 0.277 \\
\hline \multicolumn{9}{|c|}{ Father employed (age 14) } \\
\hline No & 0.182 & 0.041 & 0.139 & 0.452 & 0.170 & 0.033 & 0.124 & 0.441 \\
\hline Yes & 0.818 & 0.959 & 0.861 & 0.548 & 0.830 & 0.967 & 0.876 & 0.559 \\
\hline \multicolumn{9}{|c|}{ Father's employment (age 14) missing } \\
\hline No & 0.896 & 0.981 & 0.925 & 0.729 & 0.904 & 0.982 & 0.928 & 0.755 \\
\hline Yes & 0.104 & 0.019 & 0.075 & 0.271 & 0.096 & 0.018 & 0.072 & 0.245 \\
\hline \multicolumn{9}{|c|}{ Father's occupational status (age 14) } \\
\hline Mean ANU4 scale & 0.381 & 0.486 & 0.360 & 0.242 & 0.404 & 0.514 & 0.379 & 0.262 \\
\hline \multicolumn{9}{|c|}{ Father's occupation (age 14): other or missing } \\
\hline No & 0.835 & 0.931 & 0.857 & 0.659 & 0.853 & 0.948 & 0.864 & 0.689 \\
\hline Yes & 0.165 & 0.069 & 0.143 & 0.341 & 0.147 & 0.052 & 0.136 & 0.311 \\
\hline \multicolumn{9}{|c|}{ Number of observations } \\
\hline Total & 4079 & 1027 & 1580 & 1472 & 2362 & 692 & 913 & 757 \\
\hline Descript sample & 3527 & 898 & 1341 & 1288 & 2263 & 661 & 875 & 727 \\
\hline Regressn sample & 3342 & 871 & 1282 & 1189 & 2150 & 641 & 840 & 669 \\
\hline
\end{tabular}

All: full estimation sample; No, Mod, Ext (disadv): no, moderate, and extensive socioeconomic disadvantage; Cores: co-residing; Indpt: not co-residing with parents; Descript sample: respondents who are not in school and have nonmissing values for parental support and youth outcomes (see Tables 1 and 2); Regressn sample: respondents who are not in school and have nonmissing values for parental support, youth outcomes and all covariates (used for regression analysis). Source: Youth in Focus Survey data. Covariate (weighted) means for regression sample; weights not adjusted for sample restrictions. 
Table A2: Estimation Results for Models of Parental Support

\begin{tabular}{|c|c|c|c|c|c|c|c|c|c|c|}
\hline & \multicolumn{5}{|c|}{ Wave 1 (age 18 ) } & \multicolumn{5}{|c|}{ Wave 2 (age 20$)$} \\
\hline & Indpt & Indpt & Indpt & Cores & Cores & Indpt & Indpt & Indpt & Cores & Cores \\
\hline & & & & Loan & & & Loan & & Loan & \\
\hline \multicolumn{11}{|c|}{ Socioeconomic circumstances (base: no disadv) } \\
\hline \multirow[t]{2}{*}{ Mod disadv } & -0.057 & 0.077 & 0.842 & -0.041 & 0.345 & 0.241 & 0.188 & 0.468 & 0.076 & 0.316 \\
\hline & 0.183 & 0.271 & 0.276 & 0.126 & 0.127 & 0.209 & 0.299 & 0.198 & 0.210 & 0.148 \\
\hline \multirow{2}{*}{ Ext disadv } & -0.104 & -0.084 & 1.210 & -0.261 & 0.457 & 0.092 & 0.168 & 0.733 & -0.136 & 0.326 \\
\hline & 0.224 & 0.316 & 0.291 & 0.159 & 0.148 & 0.278 & 0.384 & 0.237 & 0.276 & 0.190 \\
\hline \multicolumn{11}{|l|}{ Age } \\
\hline \multirow[t]{2}{*}{ Months minus 220} & -0.064 & -0.180 & 0.142 & 0.029 & 0.049 & 0.078 & 0.227 & 0.204 & 0.029 & 0.027 \\
\hline & 0.064 & 0.089 & 0.063 & 0.045 & 0.041 & 0.053 & 0.071 & 0.045 & 0.054 & 0.037 \\
\hline \multicolumn{11}{|c|}{ Highest level of school completed (base: less than Year 12) } \\
\hline \multirow[t]{2}{*}{ Year 12} & -0.195 & -0.708 & -1.344 & -0.737 & -0.774 & 0.096 & -1.155 & -0.825 & -0.716 & -0.542 \\
\hline & 0.191 & 0.227 & 0.162 & 0.130 & 0.118 & 0.294 & 0.306 & 0.212 & 0.256 & 0.194 \\
\hline \multicolumn{11}{|c|}{ Home state (base: $N S W+A C T$ ) } \\
\hline \multirow[t]{2}{*}{$\mathrm{VIC}$} & -0.015 & -0.871 & -0.289 & -0.018 & -0.251 & 0.071 & -0.566 & -0.235 & 0.186 & -0.057 \\
\hline & 0.194 & 0.325 & 0.203 & 0.131 & 0.126 & 0.224 & 0.332 & 0.199 & 0.221 & 0.153 \\
\hline \multirow[t]{2}{*}{ QLD } & 0.567 & 0.563 & 0.531 & 0.262 & 0.410 & 0.605 & 0.284 & 0.608 & 0.186 & 0.328 \\
\hline & $0.19^{r}$ & 0.248 & 0.193 & 0.145 & 0.131 & 0.248 & 0.334 & 0.213 & 0.268 & 0.181 \\
\hline \multirow[t]{2}{*}{$\mathrm{SA}$} & 0.420 & -0.034 & 0.436 & -0.093 & -0.016 & 0.008 & -0.284 & 0.053 & 0.173 & -0.319 \\
\hline & 0.266 & 0.397 & 0.260 & 0.211 & 0.191 & 0.347 & 0.469 & 0.286 & 0.329 & 0.243 \\
\hline \multirow[t]{2}{*}{$\mathrm{WA}+\mathrm{NT}$} & 0.095 & 0.417 & -0.009 & 0.187 & 0.302 & -0.088 & 0.098 & 0.122 & 0.353 & 0.069 \\
\hline & 0.268 & 0.317 & 0.276 & 0.180 & 0.163 & 0.340 & 0.424 & 0.272 & 0.300 & 0.217 \\
\hline \multirow[t]{2}{*}{ TAS } & 0.766 & 0.691 & 0.450 & 0.187 & -0.096 & 0.547 & 0.729 & 0.948 & -0.813 & -0.054 \\
\hline & 0.413 & 0.510 & 0.403 & 0.352 & 0.341 & 0.511 & 0.604 & 0.416 & 0.798 & 0.416 \\
\hline
\end{tabular}

Continued next page. 
Table A2 continued

\begin{tabular}{|c|c|c|c|c|c|c|c|c|c|c|}
\hline & \multicolumn{5}{|c|}{ Wave 1 (age 18) } & \multicolumn{5}{|c|}{ Wave 2 (age 20 ) } \\
\hline & $\begin{array}{l}\text { Indpt } \\
\text { Gift }\end{array}$ & $\begin{array}{l}\text { Indpt } \\
\text { Loan }\end{array}$ & $\begin{array}{l}\text { Indpt } \\
\text { Nil }\end{array}$ & $\begin{array}{l}\text { Cores } \\
\text { Loan }\end{array}$ & $\begin{array}{c}\text { Cores } \\
\text { Nil }\end{array}$ & $\begin{array}{l}\text { Indpt } \\
\text { Gift }\end{array}$ & $\begin{array}{l}\text { Indpt } \\
\text { Loan }\end{array}$ & $\begin{array}{l}\text { Indpt } \\
\text { Nil }\end{array}$ & $\begin{array}{l}\text { Cores } \\
\text { Loan }\end{array}$ & $\begin{array}{c}\text { Cores } \\
\text { Nil }\end{array}$ \\
\hline \multicolumn{11}{|c|}{ Health status fair or poor (base: excellent, very good, or good) } \\
\hline \multirow[t]{2}{*}{ Yes } & -0.164 & 0.749 & 0.666 & 0.591 & 0.129 & 0.442 & 0.145 & 0.144 & 0.014 & -0.349 \\
\hline & 0.300 & 0.293 & 0.226 & 0.188 & 0.189 & 0.318 & 0.427 & 0.280 & 0.340 & 0.248 \\
\hline \multicolumn{11}{|c|}{ Health limits amount of work (base: no) } \\
\hline \multirow[t]{2}{*}{ Yes } & 0.401 & 0.496 & 0.589 & 0.200 & 0.137 & -0.718 & 0.180 & -0.221 & -0.007 & -0.040 \\
\hline & 0.280 & 0.332 & 0.245 & 0.213 & 0.202 & 0.403 & 0.433 & 0.296 & 0.350 & 0.243 \\
\hline \multicolumn{11}{|c|}{ Sex (base: female) } \\
\hline \multirow[t]{2}{*}{ Male } & -0.376 & 0.032 & -0.276 & 0.313 & 0.391 & 0.050 & -0.272 & 0.196 & 0.274 & 0.460 \\
\hline & 0.150 & 0.199 & 0.150 & 0.103 & 0.096 & 0.178 & 0.253 & 0.153 & 0.178 & 0.124 \\
\hline \multicolumn{11}{|c|}{ Birth year (base: 1987) } \\
\hline \multirow[t]{2}{*}{1988} & -0.483 & -0.764 & 0.082 & -0.079 & 0.017 & 0.239 & 0.331 & 0.560 & -0.012 & -0.015 \\
\hline & 0.238 & 0.331 & 0.236 & 0.168 & 0.155 & 0.236 & 0.321 & 0.201 & 0.237 & 0.165 \\
\hline \multicolumn{11}{|c|}{ Mother born overseas (base: no) } \\
\hline \multirow[t]{2}{*}{ Yes } & -0.539 & -0.394 & -0.446 & -0.352 & -0.393 & -0.565 & -0.384 & -0.604 & -0.262 & -0.298 \\
\hline & 0.195 & 0.263 & 0.197 & 0.134 & 0.123 & 0.238 & 0.335 & 0.201 & 0.226 & 0.154 \\
\hline \multicolumn{11}{|c|}{ Father born overseas (base: no) } \\
\hline \multirow[t]{2}{*}{ Yes } & -0.400 & -0.783 & -0.654 & -0.369 & -0.327 & -0.708 & -0.911 & -0.758 & -0.398 & -0.309 \\
\hline & 0.187 & 0.273 & 0.197 & 0.131 & 0.120 & 0.229 & 0.338 & 0.193 & 0.216 & 0.148 \\
\hline \multicolumn{11}{|c|}{ Ever lived with stepparent (base: no) } \\
\hline \multirow[t]{2}{*}{ Yes } & 0.096 & 0.297 & 0.432 & -0.175 & -0.040 & 0.282 & 0.420 & 0.400 & -0.036 & 0.326 \\
\hline & 0.214 & 0.258 & 0.184 & 0.171 & 0.146 & 0.305 & 0.396 & 0.250 & 0.320 & 0.231 \\
\hline
\end{tabular}

Continued next page. 
Table A2 continued

\begin{tabular}{|c|c|c|c|c|c|c|c|c|c|c|}
\hline & & War & ve 1 (age & 18) & & & $\mathrm{Wa}$ & ve 2 (age & $20)$ & \\
\hline & Indpt & Indpt & Indpt & Cores & Cores & Indpt & Indpt & Indpt & Cores & $\begin{array}{c}\text { Cores } \\
\mathrm{Nil}\end{array}$ \\
\hline Ever lived wr & arent (bo & se: no) & & & & & & & & \\
\hline Yes & 0.192 & 0.404 & 0.069 & -0.128 & 0.052 & 0.514 & -0.056 & 0.442 & 0.745 & 0.186 \\
\hline & 0.198 & 0.257 & 0.187 & 0.147 & 0.130 & 0.253 & 0.357 & 0.213 & 0.251 & 0.185 \\
\hline Ever lived 2 & arents, fo & ster pare & nts etc. & (base: $n$ & & & & & & \\
\hline Yes & 1.230 & 1.079 & 0.688 & 0.230 & 0.112 & 0.858 & 0.873 & 0.431 & -0.403 & -0.087 \\
\hline & 0.220 & 0.270 & 0.207 & 0.203 & 0.183 & 0.308 & 0.382 & 0.271 & 0.397 & 0.254 \\
\hline Mother comp & 12 (age & 14) (bas & $e: n o)$ & & & & & & & \\
\hline Yes & 0.162 & 0.455 & -0.167 & 0.050 & 0.002 & -0.145 & 0.101 & -0.060 & 0.109 & -0.191 \\
\hline & 0.163 & 0.234 & 0.173 & 0.116 & 0.108 & 0.203 & 0.275 & 0.173 & 0.202 & 0.141 \\
\hline Mother's edu & e 14) $m i$ & $\operatorname{ssing}(b a$ & se: no) & & & & & & & \\
\hline Yes & -0.009 & 1.132 & 0.627 & -0.002 & 0.200 & -0.539 & -0.884 & -0.094 & -0.113 & -0.266 \\
\hline & 0.324 & 0.333 & 0.246 & 0.228 & 0.201 & 0.444 & 0.591 & 0.315 & 0.422 & 0.280 \\
\hline Mother empl & 14) (bast & : no) & & & & & & & & \\
\hline Yes & 0.178 & 0.266 & -0.109 & 0.015 & -0.148 & 0.214 & 0.523 & -0.156 & -0.060 & -0.175 \\
\hline & 0.180 & 0.255 & 0.171 & 0.125 & 0.113 & 0.236 & 0.337 & 0.190 & 0.225 & 0.155 \\
\hline Mother's em & (age 14) & missing & (base: no & & & & & & & \\
\hline Yes & 0.016 & -0.209 & -0.566 & -0.424 & -0.626 & 0.581 & 1.246 & 0.442 & -0.301 & 0.101 \\
\hline & 0.460 & 0.523 & 0.387 & 0.346 & 0.294 & 0.645 & 0.723 & 0.486 & 0.733 & 0.445 \\
\hline Mother's occ & status (a & ge 14) (b & ase: no) & & & & & & & \\
\hline ANU4 scale & -0.125 & 0.519 & -0.165 & 0.079 & -0.381 & -0.110 & -0.472 & -0.140 & -0.179 & -0.561 \\
\hline & 0.310 & 0.424 & 0.329 & 0.220 & 0.209 & 0.419 & 0.605 & 0.377 & 0.417 & 0.299 \\
\hline
\end{tabular}

Continued next page. 
Table A2 continued

\begin{tabular}{cccccccccc}
\hline & \multicolumn{4}{c}{ Wave 1 (age 18) } & \multicolumn{4}{c}{ Wave 2 (age 20) } \\
Indpt & Indpt & Indpt & Cores & Cores & Indpt & Indpt & Indpt & Cores & Cores \\
Gift & Loan & Nil & Loan & Nil & Gift & Loan & Nil & Loan & Nil \\
\hline
\end{tabular}

Mother's occupation (age 14): other (base: no)

Yes $\begin{array}{rrrrr}-1.129 & 0.396 & -0.709 & 0.982 & -0.097 \\ 1.061 & 0.829 & 0.822 & 0.409 & 0.467\end{array}$

Mother's occupation (age 14): none or missing (wave 2 including other) (base: no)

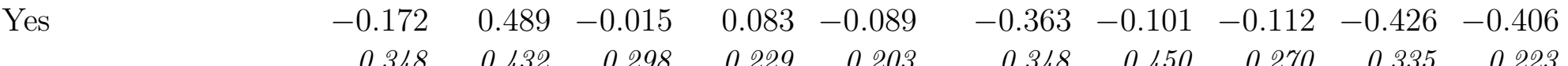

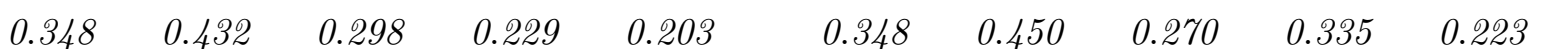

Father completed Year 12 (age 14) (base: no)

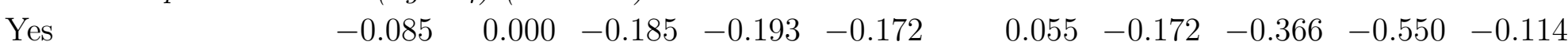

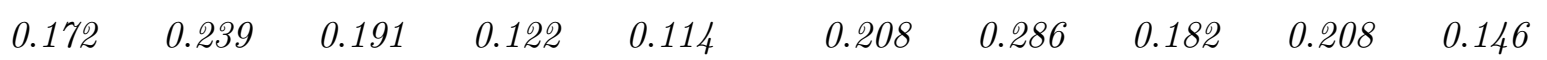

Father's education (age 14) missing (base: no)

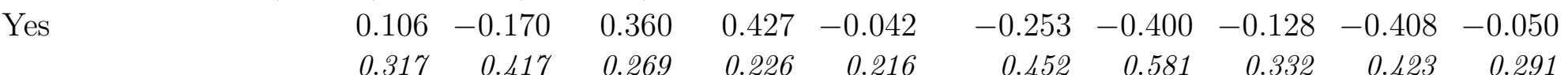

Father employed (age 14) (base: no)

Yes $\quad \begin{array}{llllllllllll}0.708 & -0.481 & -0.193 & 0.538 & 0.207 & -0.458 & -0.021 & -0.086 & -0.093 & -0.053\end{array}$

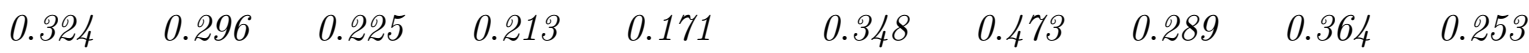

Father's employment (age 14) missing (base: no)

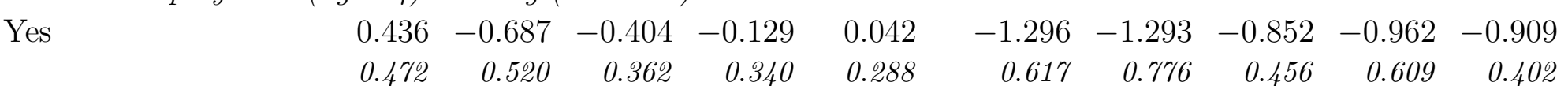

Father's occupational status (age 14)

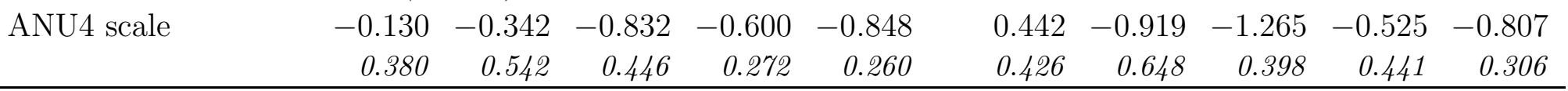

Continued next page. 
Table A2 continued

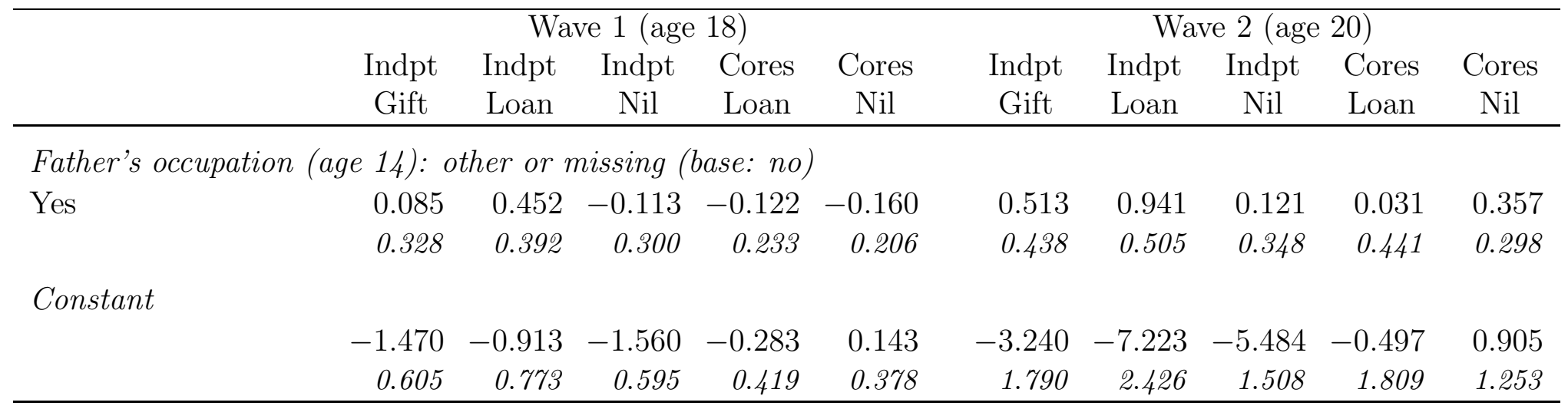

Indpt: not co-residing with parents; Cores: co-residing; Gift, loan, nil: receiving financial assistance in the form of gifts or loans, or not receiving financial assistance from parents; No, Mod, Ext disadv: no, moderate, and extensive socioeconomic disadvantage. Standard errors in italics (nonparametric bootstrap with fixed evaluation points). Source: Youth in Focus Survey data. Sample restricted to respondents who are not in school and have nonmissing values for parental support, youth outcomes and all covariates. Estimates for multinomial logit models with parameters for co-residing and receiving gifts normalized to 0. 
Table A3: Specification Tests for Models of Educational and Employment Outcomes

Wave $1 \quad$ Wave 2

(Age 18) (Age 20)

DF $\quad \mathrm{P} \quad \mathrm{DF} \quad \mathrm{P}$

Dropping variables (across all six outcomes)

Dropping socioeconomic circumstances

$\begin{array}{llll}58 & 0.0 & 60 & 80.1\end{array}$

\begin{tabular}{lllll} 
Dropping parental support & 73 & 0.0 & 75 & 0.0 \\
\hline
\end{tabular}

DF: degrees of freedom; P: p-value of likelihood ratio tests in percent; Source: Youth in Focus Survey data. Sample restricted to respondents who are not in school and have nonmissing values for parental support, youth outcomes, and all covariates. 
Table A4: Estimation Results for Models of Educational and Employment Outcomes

\begin{tabular}{|c|c|c|c|c|c|c|c|c|c|c|}
\hline & \multicolumn{5}{|c|}{ Wave 1 (age 18) } & \multicolumn{5}{|c|}{ Wave 2 (age 20$)$} \\
\hline & Stdy & Stdy & NoSt & NoSt & NoSt & Stdy & Stdy & NoSt & NoSt & NoSt \\
\hline & FtW & NoW & FtW & $\mathrm{PtW}$ & NoW & FtW & NoW & FtW & PtW & NoW \\
\hline \multicolumn{11}{|c|}{ Socioeconomic circumstances $\times$ parental support (base: extensive disadvantage, cores=1, gift=1) } \\
\hline \multirow[t]{2}{*}{ No disadv } & -0.563 & -0.869 & -0.420 & -0.611 & -1.044 & 0.255 & -0.252 & -0.031 & 0.093 & 0.248 \\
\hline & 0.304 & 0.246 & 0.283 & 0.266 & 0.356 & 0.538 & 0.357 & 0.429 & 0.503 & 0.608 \\
\hline \multirow[t]{2}{*}{ Mod disadv } & -0.041 & -0.578 & -0.300 & -0.378 & -0.723 & 0.535 & -0.205 & 0.410 & 0.051 & 0.620 \\
\hline & 0.266 & 0.219 & 0.263 & 0.242 & 0.297 & 0.525 & 0.347 & 0.398 & 0.506 & 0.553 \\
\hline \multirow[t]{2}{*}{ Cores $=1$, gift $=0$} & 0.747 & -0.277 & 0.839 & 0.332 & 0.339 & 1.334 & -0.533 & 0.812 & 0.783 & 0.564 \\
\hline & 0.262 & 0.243 & 0.251 & 0.244 & 0.263 & 0.465 & 0.337 & 0.355 & 0.433 & 0.493 \\
\hline \multirow[t]{2}{*}{ Cores $=0$, gift $=0$} & -0.155 & 0.142 & 0.298 & -0.087 & 0.171 & 1.172 & -0.426 & 0.777 & 0.749 & 0.728 \\
\hline & 0.365 & 0.310 & 0.328 & 0.322 & 0.327 & 0.502 & 0.395 & 0.389 & 0.468 & 0.512 \\
\hline \multirow{2}{*}{ Cores $=0$, gift $=1$} & -0.398 & -0.451 & -0.637 & -0.894 & -1.290 & 1.264 & 0.575 & -0.006 & -0.157 & 0.506 \\
\hline & 0.447 & 0.376 & 0.439 & 0.425 & 0.499 & 0.642 & 0.482 & 0.605 & 0.758 & 0.702 \\
\hline \multirow[t]{2}{*}{$\mathrm{N}$, Cores $=1$, gift $=0$} & 0.289 & -0.750 & -0.480 & -0.185 & -0.014 & -0.338 & -0.444 & -0.096 & -0.283 & -0.759 \\
\hline & 0.362 & 0.389 & 0.347 & 0.342 & 0.447 & 0.583 & 0.491 & 0.481 & 0.562 & 0.712 \\
\hline \multirow[t]{2}{*}{$\mathrm{N}$, Cores $=0$, gift $=0$} & 1.642 & 0.254 & 0.361 & 0.258 & -15.000 & 0.552 & 1.003 & 0.952 & 0.090 & 0.127 \\
\hline & 0.595 & 0.615 & 0.595 & 0.652 & 0.000 & 0.675 & 0.598 & 0.570 & 0.689 & 0.791 \\
\hline \multirow[t]{2}{*}{$\mathrm{N}$, Cores $=0$, gift $=1$} & 1.107 & 1.165 & 0.282 & 0.435 & 1.609 & -1.019 & -0.099 & 0.580 & -0.059 & -1.518 \\
\hline & 0.608 & 0.507 & 0.657 & 0.641 & 0.782 & 0.830 & 0.613 & 0.755 & 0.970 & 1.296 \\
\hline \multirow[t]{2}{*}{$\mathrm{M}$, Cores $=1$, gift $=0$} & -0.110 & -0.311 & -0.296 & -0.088 & -0.310 & -0.276 & -0.322 & -0.134 & 0.252 & -0.740 \\
\hline & 0.333 & 0.330 & 0.329 & 0.317 & 0.388 & 0.571 & 0.472 & 0.452 & 0.562 & 0.638 \\
\hline \multirow[t]{2}{*}{ M, Cores $=0$, gift $=0$} & 1.159 & 0.798 & 1.215 & 0.771 & 1.242 & -0.064 & 0.679 & 0.293 & -0.146 & -0.589 \\
\hline & 0.526 & 0.479 & 0.484 & 0.499 & 0.517 & 0.634 & 0.532 & 0.508 & 0.645 & 0.688 \\
\hline \multirow[t]{2}{*}{ M, Cores $=0$, gift $=1$} & 1.024 & 1.293 & 0.679 & 0.497 & 1.892 & -1.271 & 0.134 & 0.160 & -0.163 & -1.079 \\
\hline & 0.578 & 0.489 & 0.613 & 0.607 & 0.668 & 0.819 & 0.604 & 0.730 & 0.981 & 0.959 \\
\hline
\end{tabular}

Continued next page. 
Table A4 continued

\begin{tabular}{|c|c|c|c|c|c|c|c|c|c|c|}
\hline & \multicolumn{5}{|c|}{ Wave 1 (age 18 ) } & \multicolumn{5}{|c|}{ Wave 2 (age 20$)$} \\
\hline & Stdy & Stdy & NoSt & NoSt & NoSt & Stdy & Stdy & NoSt & NoSt & NoSt \\
\hline & FtW & NoW & FtW & PtW & NoW & FtW & NoW & FtW & PtW & NoW \\
\hline \multicolumn{11}{|l|}{ Age } \\
\hline \multirow[t]{2}{*}{ Months minus 220} & 0.024 & 0.057 & 0.036 & 0.092 & -0.030 & 0.136 & 0.065 & 0.179 & 0.172 & 0.283 \\
\hline & 0.052 & 0.053 & 0.052 & 0.052 & 0.062 & 0.045 & 0.048 & 0.041 & 0.050 & 0.059 \\
\hline \multicolumn{11}{|c|}{ Highest level of school completed (base: less than Year 12) } \\
\hline \multirow[t]{2}{*}{ Year 12} & -1.942 & -0.532 & -1.847 & -1.308 & -2.135 & -1.625 & -0.823 & -2.019 & -1.771 & -2.561 \\
\hline & 0.169 & 0.199 & 0.169 & 0.177 & 0.187 & 0.260 & 0.308 & 0.245 & 0.273 & 0.280 \\
\hline \multicolumn{11}{|c|}{ Home state (base: $N S W+A C T)$} \\
\hline \multirow[t]{2}{*}{$\mathrm{VIC}$} & -0.260 & -0.322 & -0.304 & -0.073 & -0.539 & -0.214 & -0.114 & -0.076 & -0.245 & -0.296 \\
\hline & 0.156 & 0.153 & 0.163 & 0.156 & 0.188 & 0.188 & 0.196 & 0.176 & 0.209 & 0.263 \\
\hline \multirow[t]{2}{*}{ QLD } & 0.178 & -0.115 & 0.559 & 0.368 & -0.000 & 0.134 & -0.105 & 0.446 & 0.211 & 0.140 \\
\hline & 0.165 & 0.172 & 0.161 & 0.165 & 0.192 & 0.205 & 0.233 & 0.191 & 0.226 & 0.275 \\
\hline \multirow[t]{2}{*}{$\mathrm{SA}$} & -0.157 & -0.107 & -0.112 & 0.105 & -0.356 & -0.209 & 0.316 & 0.168 & -0.373 & -0.082 \\
\hline & 0.240 & 0.230 & 0.244 & 0.232 & 0.275 & 0.309 & 0.287 & 0.270 & 0.361 & 0.390 \\
\hline \multirow[t]{2}{*}{$\mathrm{WA}+\mathrm{NT}$} & 0.230 & -0.462 & 0.531 & -0.113 & -0.503 & 0.184 & -0.422 & 0.591 & 0.083 & -0.021 \\
\hline & 0.201 & 0.225 & 0.195 & 0.222 & 0.269 & 0.267 & 0.322 & 0.236 & 0.295 & 0.371 \\
\hline \multirow[t]{2}{*}{ TAS } & 0.935 & 0.323 & 0.835 & 0.736 & 0.089 & -0.552 & 0.340 & -0.126 & -0.332 & 0.218 \\
\hline & 0.419 & 0.452 & 0.421 & 0.423 & 0.496 & 0.476 & 0.412 & 0.401 & 0.494 & 0.484 \\
\hline \multicolumn{11}{|c|}{ Health status fair or poor (base: excellent, very good, or good) } \\
\hline \multirow[t]{2}{*}{ Yes } & 0.176 & 0.638 & 0.041 & 0.380 & 0.280 & 0.293 & 0.078 & 0.378 & -0.080 & 0.437 \\
\hline & 0.238 & 0.224 & 0.238 & 0.225 & 0.244 & 0.301 & 0.302 & 0.269 & 0.340 & 0.338 \\
\hline \multicolumn{11}{|c|}{ Health limits amount of work (base: no) } \\
\hline \multirow[t]{2}{*}{ Yes } & -0.555 & 0.655 & -0.377 & 0.055 & 1.102 & -0.052 & 0.759 & -0.107 & 0.501 & 1.074 \\
\hline & 0.297 & 0.232 & 0.282 & 0.259 & 0.239 & 0.331 & 0.297 & 0.304 & 0.324 & 0.330 \\
\hline
\end{tabular}

Continued next page. 
Table A4 continued

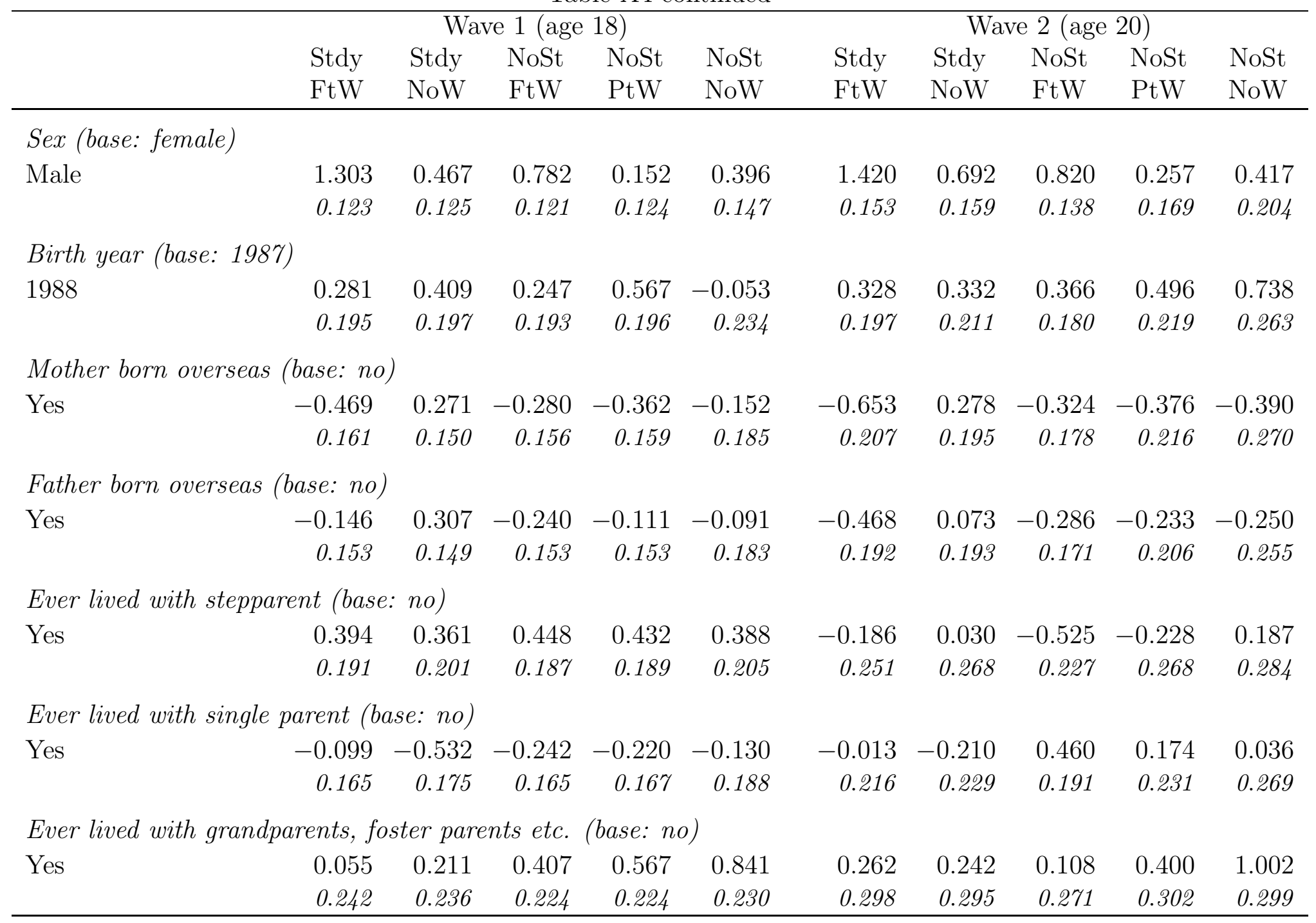

Continued next page. 
Table A4 continued

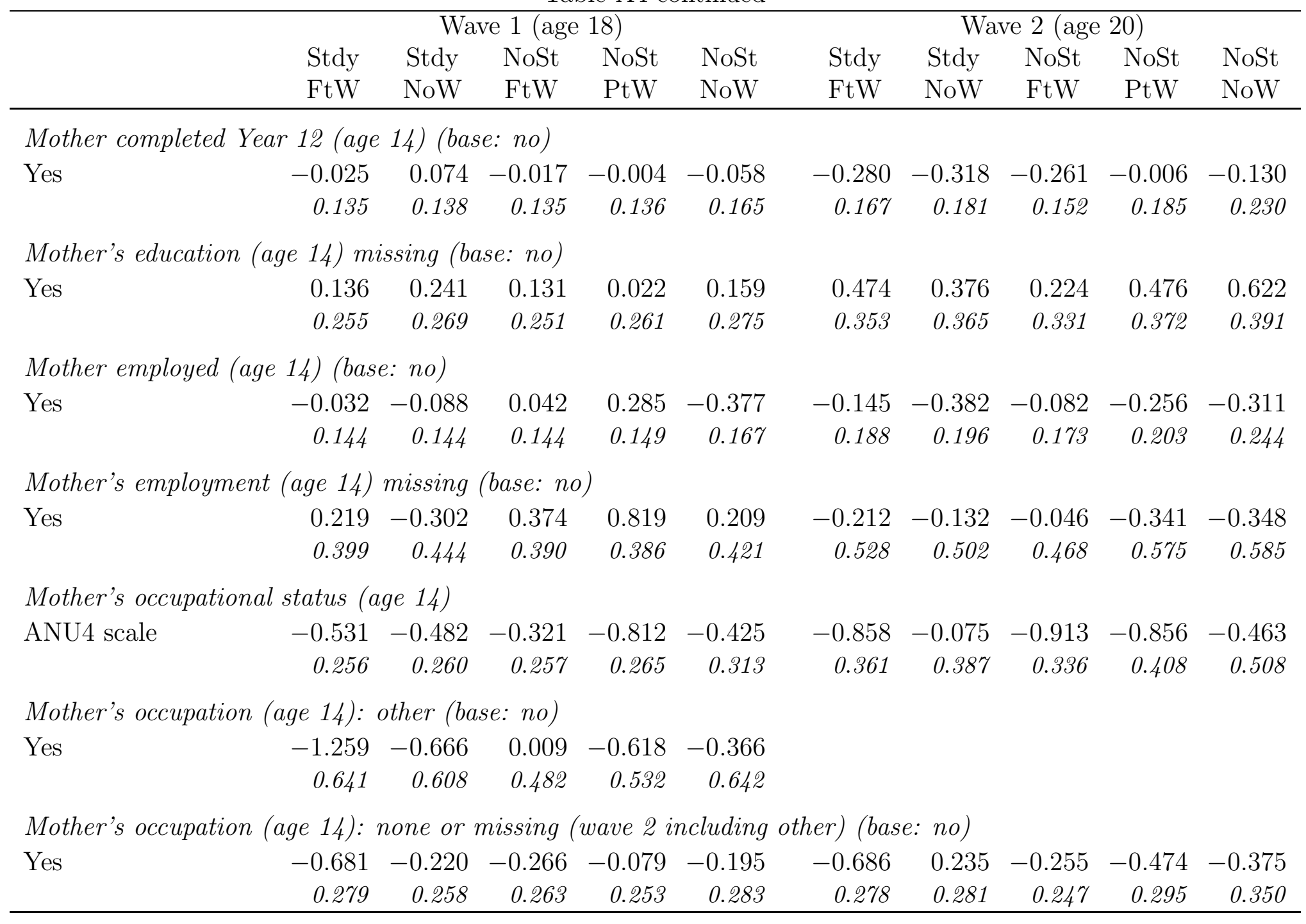

Continued next page. 
Table A4 continued

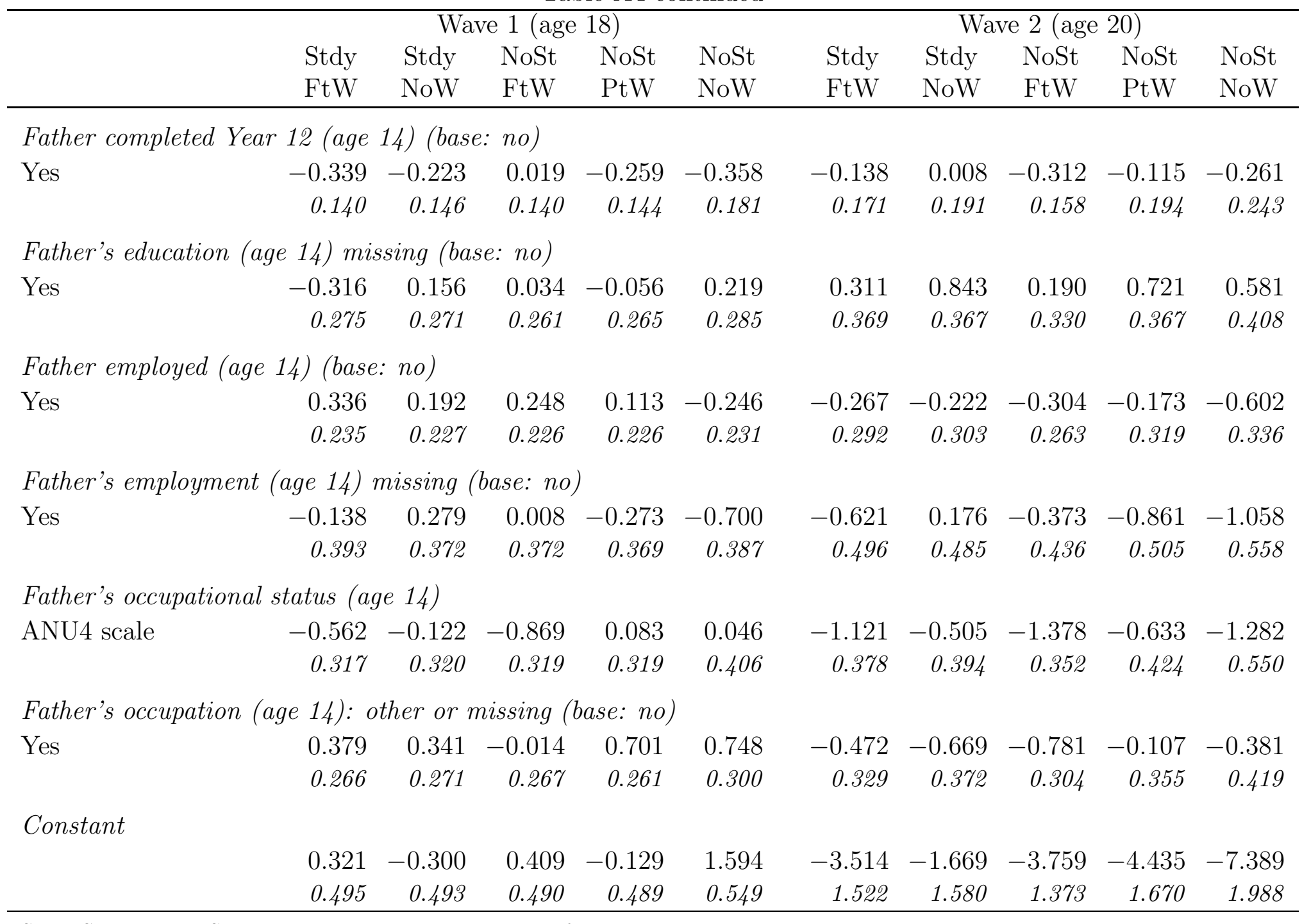

Stdy: Studying; NoSt: Not studying; FtW, PtW, NoW: full-time, part-time, and no work; No, Mod, Ext disadv: no, moderate, and extensive socioeconomic disadvantage. Standard errors in italics (nonparametric bootstrap with fixed evaluation points). Source: Youth in Focus Survey data. Sample restricted to respondents who are not in school and have nonmissing values for parental support, youth outcomes and all covariates. Part-time work includes respondents with unknown hours. Estimates for multinomial logit models with parameters for studying and working part time normalized to 0. 
Table A5: Predicted Educational and Employment Outcomes

\begin{tabular}{|c|c|c|c|c|c|c|c|c|}
\hline & \multicolumn{4}{|c|}{ Wave 1 (age 18) } & \multicolumn{4}{|c|}{ Wave 2 (age 20 ) } \\
\hline & Stdy & FtW & PtW & NoW & Stdy & FtW & $\mathrm{PtW}$ & NoW \\
\hline \multicolumn{9}{|c|}{ At observed covariates (a) } \\
\hline \multirow[t]{2}{*}{ No disadv } & 69.5 & 31.7 & 52.5 & 15.8 & 68.8 & 34.9 & 49.9 & 15.2 \\
\hline & 1.5 & 1.5 & 1.7 & 1.4 & 1.9 & 1.9 & 2.1 & 1.4 \\
\hline \multirow[t]{2}{*}{ Mod disadv } & 61.3 & 37.1 & 41.9 & 21.0 & 58.0 & 42.8 & 39.8 & 17.4 \\
\hline & 1.3 & 1.4 & 1.4 & 1.0 & 1.6 & 2.1 & 1.9 & 1.3 \\
\hline \multirow[t]{2}{*}{ Ext disadv } & 48.8 & 33.8 & 33.1 & 33.1 & 53.5 & 39.0 & 35.7 & 25.3 \\
\hline & 1.4 & 1.4 & 1.2 & 1.3 & 1.8 & 1.7 & 1.7 & 1.6 \\
\hline \multicolumn{9}{|c|}{ At socioeconomic group means of all covariates (b) } \\
\hline \multirow[t]{2}{*}{ No disadv } & 68.8 & 30.9 & 56.8 & 12.3 & 67.3 & 34.2 & 51.7 & 14.1 \\
\hline & 1.9 & 1.9 & 2.1 & 1.3 & 2.6 & 2.8 & 3.0 & 2.0 \\
\hline \multirow[t]{2}{*}{ Mod disadv } & 58.2 & 38.3 & 42.0 & 19.7 & 54.2 & 46.3 & 38.3 & 15.4 \\
\hline & 1.6 & 1.6 & 1.6 & 1.1 & 2.2 & 2.7 & 2.5 & 1.4 \\
\hline \multirow[t]{2}{*}{ Ext disadv } & 45.3 & 35.0 & 33.0 & 32.0 & 50.0 & 42.5 & 34.5 & 23.0 \\
\hline & 2.0 & 1.6 & 1.5 & 1.7 & 2.6 & 2.4 & 2.5 & 1.9 \\
\hline \multicolumn{9}{|c|}{ At socioeconomic group means of parental support, overall means of other covars (c) } \\
\hline \multirow[t]{2}{*}{ No disadv } & 64.4 & 35.4 & 51.6 & 13.0 & 60.5 & 39.3 & 44.6 & 16.1 \\
\hline & 2.3 & 2.1 & 2.2 & 1.4 & 2.9 & 3.1 & 3.2 & 2.5 \\
\hline \multirow[t]{2}{*}{ Mod disadv } & 58.4 & 37.6 & 42.6 & 19.8 & 54.9 & 45.4 & 39.2 & 15.4 \\
\hline & 1.7 & 1.6 & 1.6 & 1.1 & 2.3 & 2.7 & 2.6 & 1.5 \\
\hline \multirow[t]{2}{*}{ Ext disadv } & 52.7 & 32.7 & 38.7 & 28.6 & 59.7 & 37.5 & 43.1 & 19.3 \\
\hline & 2.0 & 2.0 & 1.9 & 1.9 & 2.7 & 2.3 & 2.7 & 2.0 \\
\hline \multicolumn{9}{|c|}{ At overall means of parental support, socioeconomic group means of other covars } \\
\hline \multirow[t]{2}{*}{ No disadv } & 69.5 & 32.6 & 56.4 & 11.0 & 66.0 & 36.4 & 49.8 & 13.8 \\
\hline & 1.9 & 2.0 & 2.2 & 1.3 & 2.6 & 2.9 & 3.0 & 1.9 \\
\hline \multirow[t]{2}{*}{ Mod disadv } & 58.4 & 38.0 & 42.0 & 20.0 & 54.5 & 45.8 & 38.4 & 15.8 \\
\hline & 1.6 & 1.6 & 1.6 & 1.1 & 2.2 & 2.7 & 2.6 & 1.5 \\
\hline \multirow[t]{2}{*}{ Ext disadv } & 45.7 & 35.0 & 33.3 & 31.6 & 51.5 & 41.1 & 34.8 & 24.1 \\
\hline & 2.1 & 1.7 & 1.5 & 1.7 & 2.9 & 2.7 & 2.7 & 2.1 \\
\hline \multicolumn{9}{|c|}{ At overall means of all covariates $(d)$} \\
\hline \multirow[t]{2}{*}{ No disadv } & 65.5 & 37.3 & 51.4 & 11.3 & 59.2 & 41.5 & 42.8 & 15.7 \\
\hline & 2.3 & 2.2 & 2.3 & 1.4 & 2.9 & 3.0 & 3.2 & 2.4 \\
\hline \multirow[t]{2}{*}{ Mod disadv } & 58.6 & 37.3 & 42.6 & 20.1 & 55.2 & 45.0 & 39.3 & 15.8 \\
\hline & 1.7 & 1.6 & 1.6 & 1.2 & 2.3 & 2.7 & 2.6 & 1.5 \\
\hline \multirow[t]{2}{*}{ Ext disadv } & 53.0 & 32.7 & 39.0 & 28.3 & 61.1 & 36.1 & 43.6 & 20.3 \\
\hline & 2.1 & 2.0 & 1.9 & 2.0 & 2.9 & 2.4 & 2.8 & 2.1 \\
\hline
\end{tabular}

Stdy: Studying (whether working or not); FtW, PtW, NoW: full-time, part-time, and no work (whether studying or not); No, Mod, Ext disadv: no, moderate, and extensive socioeconomic disadvantage; covars: covariates. Standard errors in italics (nonparametric bootstrap with fixed evaluation points). Source: Youth in Focus Survey data. Sample restricted to respondents who are not in school and have nonmissing values for parental support, youth outcomes and all covariates. Part-time work includes respondents with unknown hours. Predictions based on multinomial logit models with six categories of educational and employment outcomes (all combinations of studying and full-time/parttime/no work) evaluated at weighted sample means, see Tables A1 and A4. 